\title{
A Novel Approach to the Measurement of Bourdieusian Social Capital within Institutional Pages and Profiles
}

\author{
Uma Nova Abordagem para Mensuração de Capital Social Bourdieusiano em Páginas e \\ Perfis Institucionais
}

Kaique Matheus R. Cunha ${ }^{1}$, Guilherme Augusto da S. Ferreira ${ }^{1}$, Alan Keller Gomes ${ }^{1 \text { * }}$

\begin{abstract}
We present in this paper a novel approach for measuring Bourdieusian Social Capital (BSC) within Institutional Pages and Profiles. We analyse Facebook's Institutional Pages and Twitter's Institutional Profiles. Supported by Pierre Bourdie's theory, we search for directions to identify and capture data related to sociability practices, i. e. actions performed such as Like, Comment and Share. The system of symbolic exchanges and mutual recognition treated by Pierre Bourdieu is represented and extracted automatically from these data in the form of generalized sequential patterns. In this format, the social interactions captured from each page are represented as sequences of actions. Next, we also use such data to measure the frequency of occurrence of each sequence. From such frequencies, we compute the effective mobilization capacity. Finally, the volume of BSC is computed based on the capacity of effective mobilization, the number of social interactions captured and the number of followers on each page. The results are aligned with Bourdieu's theory. The approach can be generalized to institutional pages or profiles in Online Social Networks.

Keywords: Online Social Networks, Bourdieusian Social Capital, Sequential Patterns

Resumo: Uma nova abordagem para medir o Capital Social Bourdieusiano (CSB) contido em Páginas Institucionais do Facebook e Perfis Institucionais do Twitter é apresentada neste artigo. Baseados na teoria de Pierre Bourdieu, dados relacionados às práticas de sociabilidade em rede, i. e., dados relacionados com a execução de ações como Curtir, Comentar e Compartilhar, são identificados e capturados. O sistema de trocas simbólicas e reconhecimento mútuo tratado por Bourdieu é representado e extraído automaticamente desses dados no formato de padrões sequenciais generalizados. Nesse formato, as interações sociais capturadas de cada página são representadas como sequências de ações. A frequência de ocorrência de cada sequência é computada e, a partir dela, a capacidade de mobilização efetiva de cada página é calculada. Por fim, o volume de CSB é computado utilizando-se a capacidade de mobilização efetiva, o número de interações sociais capturadas e o número de seguidores de cada página. Os resultados estão alinhados com a teoria de Bourdieu. A abordagem pode ser generalizada para páginas ou perfis institucionais em Redes Sociais Online.

Palavras-Chave: Redes Sociais Online, Capital Social Bourdieusiano, Padrões Sequenciais

${ }^{1}$ Câmpus Inhumas - Instituto Federal de Educação, Ciência e Tecnologia de Goiás (IFG), Inhumas - Goiás, Brasil

*Corresponding author: alan.gomes@ifg.edu.br

DOI: http://dx.doi.org/10.22456/2175-2745.110111 • Received: 22/12/2020 • Accepted: 08/10/2021

CC BY-NC-ND 4.0 - This work is licensed under a Creative Commons Attribution-NonCommercial-NoDerivatives 4.0 International License.
\end{abstract}

\section{Introdução}

As Redes Sociais Online (RSO) são redes digitais que possibilitam a formação, a manutenção e a expansão de conexões sociais entre pessoas, marcas e instituições. Essas redes têm promovido e acompanhado as mudanças profundas pelas quais passam nossa sociedade e se tornaram ferramentas de comunicação e interação social de extrema importância. Por exemplo, com as providências de isolamento e distanciamento impostas para controle da pandemia do novo Corona vírus, as RSO desempenham um papel crucial no fortalecimento das relações do mundo físico em ambiente virtual. Esses laços se mantiveram e se intensificaram, ao mesmo tempo que novos laços sociais surgiram e se fortaleceram dentro dessas redes.

A manutenção e o fortalecimento desses laços se dão tanto sob o aspecto do divertimento quanto da igualdade de poder para execução das funcionalidades típicas desses ambientes [1] tais como Publicar, Curtir, Comentar e Compartilhar. Essa execução dessas funcionalidades possui um significado especial no âmbito da Sociologia Digital [2]: elas apontam para práticas de sociabilidade em rede [3] [1].

Segundo o sociólogo Pierre Bourdieu [4], essas práticas 
dentro das redes viabilizam a formação, a manutenção e a dinâmica das relações entre agentes (i.e., Páginas ou Perfis Institucionais) e sua rede de conexões sociais (i.e., seguidores) no campo (i.e., Rede Social Online). O capital acumulado a partir de uma rede de relações estabelecida em um determinado campo é denominado como Capital Social.

Esse tipo de capital é o agregado de recursos reais ou potenciais, que estão ligados à posse de uma rede durável de relações, na qual os indivíduos se reconhecem mutuamente e realizam trocas materiais e/ou simbólicas [4]. O reconhecimento mútuo e as trocas caracterizam a participação dos indivíduos dentro do grupo (rede de conexões) [4]. As RSO oferecem novas formas de acumulação de Capital Social (CS), bem como o acesso a recursos que não estão facilmente disponíveis no mundo físico para manutenção das relações [5].

Ademais, Bourdieu destaca que a manutenção e expansão do CS pressupõe um esforço incessante de sociabilidade, ou seja, um esforço contínuo para manutenção e expansão tanto da rede de conexões quanto do reconhecimento e das trocas [4] que, dentro das RSO, são cristalizados a partir da execução das funcionalidades intrínsecas à rede. Sob essa perspectiva, o Capital Social Bourdieusiano (CBS) é relacional, ou seja, baseado na conexão social, e, além disso, interacional, ou seja, baseado em interações sociais que emergem do reconhecimento e das trocas [6] [7]. Ainda é uma lacuna uma forma de apuração de CS que leva em consideração as interações sociais cristalizadas dentro de uma RSO.

Um esforço equivocadamente empregado nas redes digitais para o aumento do Capital Social é o aumento artificial (não-natural ou não-orgânico) do número de seguidores, quer seja pela adoção inapropriada de estratégias ligadas ao marketing de influência [8] por exemplo, ou até mesmo pela aquisição de número de seguidores, geralmente, robôs ou perfis de usuários não autênticos [9]. O insucesso desse esforço é evidente, pois não basta ter muitos seguidores (uma rede de conexões ampla) sem que esses indivíduos interajam entre si, estimulados incessantemente por um agente.

No presente estudo, investiga-se a hipótese de que o Capital Social Bourdieusiano, acumulado por uma Página Institucional na rede Facebook ou um Perfil Institucional na rede Twitter, pode ser medido a partir de dados sobre a execução de funcionalidades típicas da RSO executadas por seguidores. Essas páginas ou perfis analisados na abordagem se abstem da adoção de esforços equivocados para a manutenção e expansão do Capital Social, seguindo diretrizes próprias e do governo federal brasileiro ${ }^{1}$.

Estendendo trabalhos anteriores [10] [11], o objetivo geral deste artigo é apresentar uma abordagem de mensuração do volume de Capital Social Bourdieusiano acumulado dentro de Páginas e Perfis Institucionais. Na validação da abordagem de apuração do CSB aqui proposta, foi elaborado um experimento no qual foram analisadas 27 Páginas Institucionais da rede Facebook. Na generalização da abordagem, são discuti-

\footnotetext{
${ }^{1}$ www.governodigital.gov.br/transformacao/compras/orientacoes/orientacoesredes-sociais-1
}

dos resultados obtidos a partir da análise de 13 Perfis Institucionais da rede Twitter, apresentados em detalhes em [12].

Uma contribuição relevante é a representação e a extração automática do sistema de trocas e reconhecimento mútuo, tratado por Bourdieu, fazendo uso de conjuntos de dados relacionados com as práticas de sociabilidade em rede e um algoritmo de Aprendizado de Máquina que extrai sequências de ações. Outra contribuição importante é a utilização das frequências de ocorrência das sequências como base para a proposição de uma medida da capacidade de mobilização efetiva de cada agente Página ou Perfil Institucional estudado. Outra contribuição de destaque é representação do esforço incessante de sociabilidade a partir do equilíbrio entre a capacidade de mobilização efetiva, o número de interações sociais capturadas e o número de seguidores de cada página ou perfil. Esse representação do esforço de sociabilidade está diretamente relacionado com a proposição da medida do volume de Capital Social Bourdieusiano. A principal contribuição desta pesquisa é a abordagem de mensuração do volume de CSB que pode ser generalizada para páginas ou perfis institucionais em Redes Sociais Online.

Os resultados obtidos estão alinhados com a teoria de Bourdieu no que se refere 1) a representação do sistema de trocas entre agentes e sua rede de conexões, 2) a capacidade de mobilização efetiva que não é proporcional ao número de interações sociais capturadas, 3 ) a capacidade de mobilização efetiva do agente que independe do tamanho da sua rede de relacionamentos, 4) a capacidade de mobilização efetiva que não é convertida automaticamente em CSB, e 5) a manutenção e expansão do Capital Social pressupõe um esforço incessante de sociabilidade.

É importante observar que os dados coletados se referem a informações públicas e não pertencem ao perfil individual de qualquer seguidor de qualquer uma das páginas estudadas. As informações coletadas são mantidas sem identificação do usuário que a produziu. Os padrões sequenciais generalizados são extraídos automaticamente a partir de dados relacionados com as práticas de sociabilidade em rede, refletem comportamentos coletivos e impessoais.

Este trabalho está organizado da seguinte forma: Seção 2 destaca os fundamentos da Sociologia Digital, e ainda, estudos e abordagens de mensuração do Capital Social dentro de RSO; Seção 3 detalha a metodologia desenvolvida e empregada na obtenção dos resultados; Seção 4 apresenta e discute os resultados obtidos a partir da aplicação da abordagem aqui apresentada; e Seção 6 apresenta a conclusão e limitações.

\section{Sociologia Digital, Capital Social e Re- des Sociais Online}

As origens do Capital Social e suas aplicações na sociologia moderna tem sido estudada a partir dos escritos de Bourdieu [4], Coleman [13], Lin [14] e Putnam [15], conforme apresenta Recuerdo em [5], além da contribuição dos autores Granovetter [16] e Burt[17]. As contribuições de Bourdieu são fundamentais para o fortalecimento da Sociologia Digi- 
tal [2] como campo de estudo das práticas comunicacionais e interacionais dentro das RSO.

Nesta Seção são apresentados os principais marcos teóricos que fundamentam a Sociologia Digital como campo de estudo na sociologia moderna, com destaque para as contribuições de Bourdieu. Em seguida, são destacados trabalhos relacionados que tratam da mensuração do Capital Social dentro das RSO, apresentando um panorama com as principais abordagens e técnicas empregadas.

\subsection{Sociologia Digital: Fundamentação}

No ano de 2000, o sociólogo Andrew Abbott apresentou um conjunto de desafios para o futuro da sociologia [18]. Dentre esses desafios, ele destaca que as transformações tecnológicas e a produção massiva de dados provocariam mudanças importantes, pois os comportamentos sociais seriam conduzidos no meio eletrônico e os dados produzidos nesses espaços poderiam ser medidos de forma mais precisa.

A inquietação de Abbott estava centrada não apenas em relação ao número de comportamentos sociais que a tecnologia havia tornado virtualmente ilimitado, mas especialmente em relação ao grande número de variáveis que se tornariam acessíveis em poucas operações. Abbott ainda destacou que as ciências sociais empíricas teriam o desafio de encontrar padrões nesses dados sociais monumentalmente detalhados.

Mais tarde, em 2009, o termo Sociologia Digital foi primeiramente delineado pelo professor Jonathan Wynn [19]. Nesse artigo, o professor elenca uma série de desafios que surgem nos estudos sociológicos a partir das transformações tecnológicas provocadas pelos usos das mídias sociais, ressaltando, principalmente, a potencial desigualdade entre os que podem e os que não podem ter acesso a essas tecnologias.

Em alinhamento com os apontamentos de Abbott, Wynn destaca o desafio de enfrentar uma realidade em que os comportamentos sociais são conduzidos pelo uso da tecnologia, bem como, as transformações da sociologia no ambiente acadêmico, que passa a ter a disposição um volume gigantesco de dados detalhados, sobre comportamentos sociais. Wynn ainda aponta alguns benefícios que essas transformações tecnológicas podem trazer para os estudos do mundo social.

Em 2014, foi publicado o livro de Debora Lupton [20] com foco central a constatação das mudanças digitais em absolutamente todos os fenômenos de estudo da sociologia, argumentando que o estudo das tecnologias digitais precisa ser central em suas atribuições, dado que as pessoas vivem em uma sociedade digital, e isso coloca desafios urgentes à teoria e prática sociológicas.

A Sociologia Digital é definida por Lupton em termos de práticas digitais profissionais e análises focadas no uso de tecnologia e dados digitais, fazendo conexões explícitas com outras áreas do conhecimento, tais como, antropologia digital, estudos culturais, comunicação de massa e mídia, da saúde, da economia, do emprego, da educação, do trabalho, do gênero, do risco, do envelhecimento, da raça e etnicidade [20] .

Recentemente, em 2017, Ignatow \& Robinson se apoiam no arcabouço teórico do sociólogo Pierre Bourdieu para trazer as pesquisas em ciências sociais para uma abordagem baseada nas relações entre indivíduos no estudo da vida social [2]. Eles definem a Sociologia Digital como um ramo de pesquisa que trata tanto dos aspectos e impactos sociais das tecnologias de comunicação digital, quanto da aplicação de tecnologias digitais para as metodologias de pesquisa em ciências sociais.

A pesquisa aqui apresentada está baseada na vertente da Sociologia Digital que se apoia nos estudos do sociólogo Pierre Bourdieu [4] [21] [22]. Nessa perspectiva, três conceitos são fundantes de entendimento da vida social: o campo, o hábitus e o capital. Esses conceitos formam a base teórica e metodológica de investigação das estruturas sociais.

Começando pelo campo, que para Bourdieu compõe um universo social construído a partir de agentes, instituições, e materiais simbólicos específicos que indicam as regras e o funcionamento do meio, compondo uma espécie de jogo social [21]. O comportamento dos agentes nesse meio é determinante na estruturação do campo, tanto em suas características simbólicas, como na disposição de poder. A percepção da conduta dos agentes pode ser mensurada por suas práticas sociais, que constituem o hábitus, e que pode ser entendido como um sistema de disposições, modos de perceber, de sentir, de fazer, de pensar, que nos levam a agir de determinada forma em uma circunstância dada [23]. O hábitus é incorporado pelos agentes a partir de sua estrutura de convenções e experiências, reproduzido inconscientemente, caracterizando assim a estrutura do campo a partir das práticas dos agentes [21].

Por fim, completando esse conjunto relacional e interdependente de conceitos, o capital, que indica o acúmulo de poder no meio social (campo), que permite sua mensuração através da ideia de concentração de formas de poder em determinados agentes, refletindo não somente a estrutura econômica de bens, mas sim um complexo conjunto de formas de representação e apropriação do poder no meio social.

Bourdieu cita ao menos três formas em que o capital pode se manifestar: o Capital Econômico, referindo-se a própria condição financeira, expresso em vias monetárias; o Capital Cultural, caracterizado pelas formas simbólicas de representação do poder, como certificados, marcas, arte entre outras, e pode ser convertido em econômico e vice e versa; e o Capital Social, que corresponde às relações sociais, e sua valoração perante o campo, sendo esse capital o agregado dos recursos e valores que estão ligados a posse de uma rede durável de relações de conhecimento e reco- nhecimento mútuos, ou seja, da participação de indivíduos em um grupo.

As RSO oferecem novas formas de acumulação das diferentes formas de capital, bem como, acesso a recursos que não estão facilmente disponíveis no mundo real, permitindo a manutenção das relações sociais no espaço online [5]. Para Bourdieu [4], o Capital Social é instituído a partir das práticas de sociabilidade em rede, que se cristalizam a partir do reconhecimento mútuo e das trocas realizadas entre os agentes em um determinado campo.

A realização das trocas advém do reconhecimento mútuo 
de integrantes da rede de conexões e dependem da capacidade de mobilização do agente e do seu esforço incessante de sociabilidade [4]. No caso das RSO, o reconhecimento mútuo e as trocas são cristalizadas a partir da execução de ações típicas desses ambientes digitais tais como publicar, curtir, comentar e compartilhar. Portanto, agentes com capacidade de mobilização da sua rede de conexões, são capazes de estimular seus seguidores para se reconhecerem mutuamente e realizarem trocas a partir da execução de ações, ou seja, são capazes de estimular interações sociais entre usuários.

A manutenção e o crescimento do Capital Social dependem de um esforço incessante de sociabilidade [4] . No caso das RSO, esse esforço é percebido pelo número de interações sociais que cada Página Institucional se dispõe a provocar. $\mathrm{O}$ volume do capital social de um agente depende da sua capacidade de mobilização sua rede de conexões, estimulando as trocas e o reconhecimento mútuo entre integrantes da sua rede de conexões. Por outro lado, Bourdieu menciona que a capacidade de mobilização efetiva do agente independe do tamanho da rede de relacionamentos [4].

\subsection{Mensuração do Capital Social em RSO}

Além de Bourdieu [4], outros autores estudaram o Capital Social e não chegaram em um consenso sobre como medir esse tipo de capital [13] [15] [14]. Uma das primeiras medições do Capital Social em RSO, de Kazienko \& Musiał em [24], trata de uma medida do Capital Social de um usuário, composta de uma parte estática e outra dinâmica.

A parte estática corresponde aos interesses e características demográficas do usuário, ou seja, informações que não mudam ao longo do tempo. A parte dinâmica corresponde a atividade de formação e manutenção das relações do usuário e sua posição dentro da RSO. A medida é formalizada em uma equação que indica a importância e posição particular de um indivíduo. Na composição dessa medida, eles não levam em conta a execução de funcionalidades típicas dentro da rede.

Apoiados em Putnam [15], Ellison et al. [25] apresentam três medições para compor o Capital Social- ponte, vínculo e manutenção de capital - que foram criadas adaptando-se escalas existentes em uma análise de regressão sobre dados demográficos dos usuários, dados ligados ao uso da rede Facebook, e ainda, dados sobre as conexões dos usuários. No trabalho de Eloire [7] é apresentado um framework analítico para medir empiricamente o Capital Social Bourdieusiano, que leva em conta a estrutura das conexões sociais e os efeitos da interação entre usuários que formam as conexões sociais.

A partir do estudo de pensamentos e impressões do público jovem sobre o uso de mídias sociais, suas ações e interações sociais, além dos efeitos das mudanças nas suas vidas offline; Dyer em [26] destaca que as interações sociais nessas redes digitais são cada vez mais diferenciadas e multifacetadas e, portanto, uma abordagem para computar o Capital Social precisa levar em conta as interações entre usuários que emergem da execução das funcionalidades presentes na RSO.

Os esforços de medição do Capital Social dentro das RSO de Kazienko \& Musiał [24], Ellison et al. [25] e de Eloire [7], combinam a análise de dados demográficos e atitudinais dos usuários, esses dados geralmente coletados a partir da aplicação de questionários (surveys); com a análise de dados coletados diretamente da rede digital, que não estão associados com as interações que se cristalizam a partir da execução das funcionalidades típicas das RSO. O foco desses esforços é medir a composição do Capital Social a partir do estabelecimento, manutenção e expansão da rede de conexões, portanto, são esforços focados na estrutura da rede.

Nesses trabalhos, a estrutura da rede de conexões é inferida a partir dos dados coletados, medidas dessa estrutura são calculadas e associadas ao Capital Social. São utilizadas medidas de Redes Complexas tais como Centralidade, $\mathrm{Be}$ tweeness, etc, e ainda, escalas e correlações estatísticas. Uma limitação dessa abordagem está na inferência da estrutura da rede a partir dos dados, que nem sempre preserva todas as conexões estabelecidas dentro da RSO. Além disso, as interações sociais que emergem da execução de funcionalidades típicas das RSO são fundamentais para a manutenção e expansão do Capital Social acumulado no meio digital [6].

Ainda é uma lacuna, nas pesquisas que tratam do Capital Social acumulado nas RSO, a ausência de uma medida simples e direta, formalizada a partir de uma equação, que permita o cômputo do volume de CS com foco nas interações sociais emergentes de funcionalidades intrínsecas à rede digital, além de preservar a estrutura das conexões da RSO.

Recentemente, a atividade dos usuários dentro das RSO tem sido analisada utilizando-se técnicas de Aprendizado de Máquina. Baseados Lin [14], Schams et al. [27] obtém um score a partir dos dados da atividade dos usuários e esse score é associado ao Capital Social de um usuário. Inspirados em Bourdieu [4], Su \& Chan [28] examinam o compartilhamento de informações, a auto apresentação e a expressão de opinião, na criação de um modelo preditivo capaz de avaliar o impacto dessas informações na composição do Capital Social dos usuários dentro do Facebook.

Os trabalhos de Ellison et al. [25] e de Eloire [7], Schams et al. [27] e Su \& Chan [28] têm como lacunas: a) ausência da formalização das suas medidas em uma equação; b) não levam em conta as interações sociais que emergem da execução de funcionalidades típicas da RSO; e c) não preservam a estrutura de conexões da RSO, usando dados auto-reportados ou coletados automaticamente na inferência dessa estrutura. As abordagens empregadas na construção de suas medidas são complexas, não podem ser obtidas de forma simples e direta, além da ausência de representação, avaliação e incorporação das interações sociais emergentes da execução de funcionalidades da RSO na composição de suas medidas. Essas limitações são superadas no presente estudo.

A abordagem aqui apresentada toma proveito das implicações decorrentes do estudo do grafo da atividade dos usuários como um subgrafo da rede de conexões [29] [30] para propor uma medida do volume do Capital Social Bourdieusiano dentro da RSO. De acordo com esses autores, o 
grafo da atividade dos usuários (grafo de interação) de uma RSO é um subgrafo da rede de conexões (grafo social).

Sob o aspecto relacional, não há inferência da estrutura da rede de conexões sociais a partir de dados auto-reportados ou coletados da rede digital, ao contrário, a estrutura da rede de conexões é mantida. Sob o aspecto interacional, as interações sociais são extraídas automaticamente dos dados capturados, no formato de padrão sequencial generalizado, aqui chamado de sequências de ações; e em seguida, a frequência de ocorrência de cada sequência é calculada e, por fim, utilizada na composição da medida do volume de CSB.

Trabalhos anteriores dos autores desta pesquisa são estendidos no presente artigo. Em Cunha \& Gomes [10] é apresentado uma abordagem de mensuração da capacidade de mobilização de Páginas Institucionais no Facebook. No trabalho seguinte [11], um indicador de acúmulo de Capital Social é construído e utilizado, juntamente com o número de interações sociais capturadas, para computar o volume de CS acumulado em Páginas Institucionais no Facebook, sem considerar o número de seguidores.

Uma abordagem para computar o Capital Social Bourdieusiano, considerando a capacidade de mobilização efetiva, o número de interações sociais e o número de seguidores, com foco em caracterizar o esforço incessante de sociabilidade desprendido em Páginas Institucionais no Facebook é apresentada por Cunha, Costa \& Gomes em [31]. A partir da análise de Perfis Institucionais da rede Twitter, Ferreira \& Gomes apresentam um processo sistemático para computar o volume de CSB em [12].

\section{Metodologia}

No presente estudo, dados sobre as práticas de sociabilidade em rede (interações sociais) são coletados automaticamente a partir de uma estratégia que se apoia no arcabouço teórico de Bourdieu. Após a coleta, os dados são processados para serem utilizados na extração automática de interações sociais no formato de sequências de ações e na mensuração da frequência de ocorrência desses padrões sequenciais. Em um trabalho anterior [10], as frequências de ocorrência das sequências de ações estão associadas com a capacidade que cada Página Institucional (agente) possui de mobilizar seus seguidores (capacidade de mobilização).

$\mathrm{Na}$ pesquisa aqui apresentada, a efetividade da participação dos indivíduos dentro do grupo é caracterizada por um conjunto de pesos, que levam em conta o número de ações executadas pelos seguidores de cada página em cada interação social. Esses pesos são aplicados nas frequências de ocorrência das sequências de ações. Dessa forma, é construída uma medida capacidade de mobilização efetiva do agente. Essa medida, juntamente com o número de interações sociais capturadas e o número de seguidores, são utilizados para medir o volume de Capital Social Bourdieusiano acumulado em Páginas Institucionais no Facebook [31] ou em Perfis Institucionais no Twitter [12].

\subsection{Recorte da pesquisa}

Dentro das RSO, a ação de Publicar inicia uma interação social. Essa ação também é chamada de estímulo social [32]. Na Psicologia Social [33], cada publicação seguida da execução, ou não, de ações, pode ser compreendida como uma contingência comportamental, ou também, uma interação social [34] [35]. Na Sociologia Digital [2], as práticas de sociabilidade dos agentes (i.e., Página Institucional) e sua rede de conexões (i.e., seguidores) no campo (i.e., Rede Social Online) são cristalizadas a partir da execução de funcionalidades intrínsecas à rede digital, aqui chamadas de Ações.

$\mathrm{Na}$ rede Facebook, logo após a execução da ação de Publicar, as ações Curtir, Comentar e Compartilhar ficam disponíveis e podem ser executadas em qualquer ordem pelos usuários conectados ao provedor do estímulo social. Atualmente, o registro da execução dessas ações (cristalização das práticas de sociabilidade) é feito apresentando-se o número de curtidas, o número de comentários e o número de compartilhamentos (internos) em cada publicação. No número de curtidas, é contabilizado o registro da execução de diferentes reações, cada uma caracterizada por um ícone ou emoji. O compartilhamento de uma publicação pode ser feito para dentro e para fora do Facebook. A ação de compartilhar aqui analisada, restringe-se apenas ao compartilhamento interno.

Foram escolhidas, como objeto de estudo, Páginas Institucionais (fanpages) de duas instituições públicas federais de ensino profissional do Brasil. O Instituto Federal de Goiás (IFG) é uma instituição com 14 campi e o Instituto Federal de Goiano (IFGoiano) é uma instituição com 13 campi, ambos institutos presentes no Estado de Goiás. Seguindo diretrizes internas, e ainda, diretrizes do governo federal brasileiro, cada um desses campi tem autonomia para gerir sua fanpage.

Nessas diretrizes há, por exemplo, restrições expressas quanto a adoção de medidas que provoquem o aumento nãonatural ou não-orgânico do número de seguidores das páginas. Há recomendações para que sejam evitadas publicações com conteúdo ofensivo, conteúdo controverso ou que possa provocar algum tipo de polêmica, além do conteúdo cuja fonte não possa ser averiguada ou que possa ser potencialmente enquadrado como notícia falsa (fake news).

Além disso, cada página é sempre o único provedor de estímulos sociais e seus seguidores podem interagir somente executando as ações Curtir, Comentar e Compartilhar. Como estratégia de inclusão de novos seguidores, aos não seguidores da página, as ações Curtir, Comentar e Compartilhar também ficam disponíveis. Acredita-se que, um usuário da rede que curte, comenta ou compartilha algum conteúdo dessas páginas, dificilmente não se torna seguidor. As diretrizes são importantes para uniformizar os esforços de sociabilidade dos agentes e para garantir que os resultados obtidos a partir da aplicação da abordagem aqui apresentada possam ser comparáveis entre si.

Uma visão geral da metodologia empregada nesta pesquisa é apresentada na Figura 1. Em cada passo são descritos os materiais e métodos utilizados, conforme detalhado a seguir. 


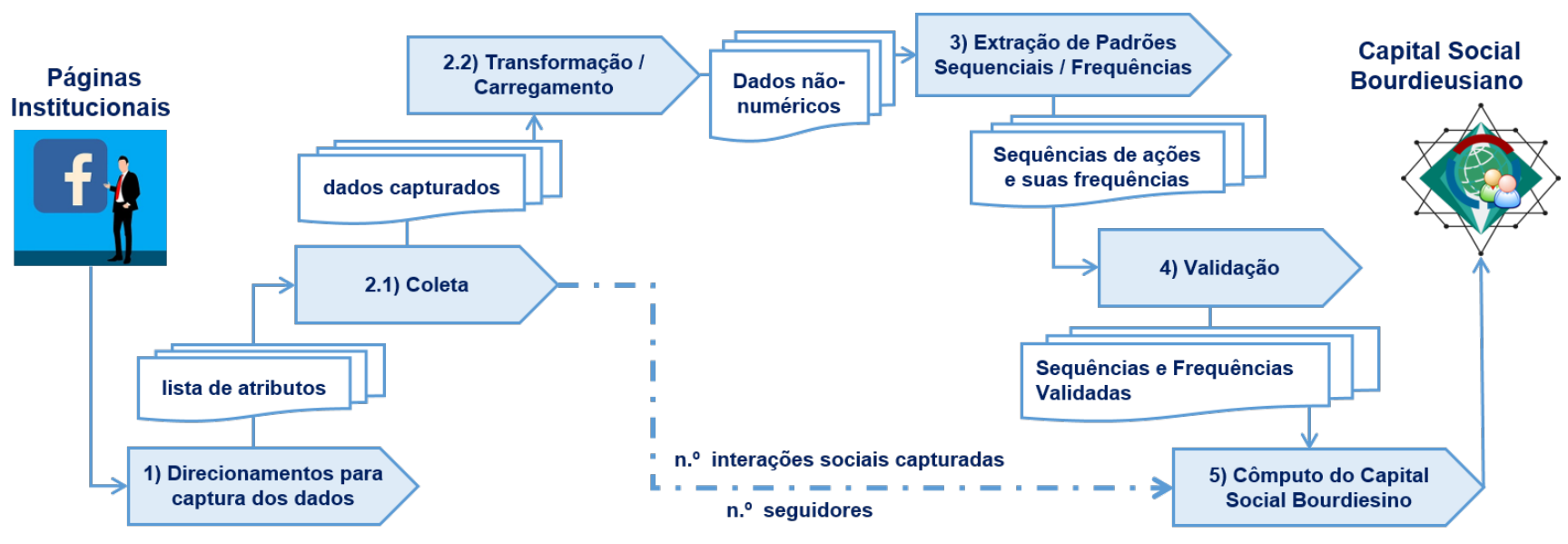

Figura 1. Visão geral dos procedimentos empregados da metodologia

\subsection{Direcionamentos para captura dos dados}

A concepção de Bourdieu [4], no âmbito da Sociologia Digital [2], a respeito das práticas de sociabilidade em rede, foi utilizada no direcionamento dos esforços na etapa de identificação dos dados a serem capturados.

As funcionalidades de interação e comunicação que apontam para as práticas de sociabilidade em rede foram identificadas, para esta pesquisa, como sendo as ações Publicar, Curtir, Comentar e Compartilhar. Como registro das práticas de sociabilidade cristalizadas foi identificado o número de curtidas, o número de comentários e o número de compartilhamentos (internos). Cada publicação, seguida ou não da execução subjacente das ações Curtir, Comentar e Compartilhar, foi identificada como sendo uma interação social. Esses direcionamentos são empregados no passo 1 da Figura 1.

\subsection{Coleta, transformação e carregamento}

$\mathrm{Na}$ etapa de coleta, transformação e carregamento dos dados identificados anteriormente, foi empregado o método ETL (Extract/Transform/Load) [36]. A coleta, transformação e carregamento dos dados estão apresentados nos passos 2.1 e 2.2 da Figura 1. O acesso aos dados é feito utilizando-se a API Facebook ${ }^{2}$ durante o mês de janeiro de 2018. Foram coletados dados de todas as publicações (interações sociais) desde a data de criação de cada página institucional. O passo de coleta dos dados está apresentado em 2.1 na Figura 1.

Atualmente, a API Facebook bloqueia o acesso aos dados de fanpages. Para contornar esse problema, até a liberação do acesso, é utilizando-se Selenium ${ }^{3}$ para coleta. Por conta do bloqueio imposto no acesso a dados atuais via API, optouse por não exibir resultados da aplicação da abordagem aqui apresentada utilizando-se dados coletados via Selenium. Esses resultados com dados atuais não são imprescindíveis para apresentação da abordagem, pois a aplicação desta independe do lapso temporal no qual os dados foram coletados.

\footnotetext{
${ }^{2}$ https://developers.facebook.com.

${ }^{3}$ https://www.seleniumhq.org/
}

Scripts na linguagem Python ${ }^{4}$ foram implementados para o processamento do método ETL e os dados foram armazenados em um banco de dados MySQL ${ }^{5}$. O passo de transformação e carregamento dos dados está apresentado em 2.2 na Figura 1. Foi construída uma base de dados para cada página dentro do MySQL. Os dados capturados foram transformados para a etapa de extração de sequências de ações. Esses dados transformados foram carregados em uma outra base de dados que contém valores não-numéricos. A manipulação exclusiva de valores não-numéricos é uma restrição imposta pelo algoritmo de extração de padrões sequenciais generalizados.

\subsection{Padrões Sequenciais de Ações}

Uma implementação do algoritmo GSP (Generalized Sequential Pattern) [37] foi elaborada para a extração automática de interações sociais no formato de padrões sequenciais de ações, aqui chamados de sequências de ações. O GSP é um algoritmo de AM que explora o aprendizado por associação em conjuntos de dados que possuem uma inerente natureza sequencial. Essa natureza sequencial significa que há uma relação ordinal entre eventos que estão expressos nesses dados, enfatizando somente relações de co-ocorrência baseada em uma precedência temporal ou espacial.

Em termos gerais, no aprendizado de padrões sequenciais generalizados, uma sequência é uma lista ordenada de elementos [38]. Dentro da rede Facebook, uma interação social pode ser vista como uma lista ordenada de elementos. Assim que é feita uma publicação, os seguidores conectados a uma Página Institucional podem executar, ou não, ações Curtir, Comentar e Compartilhar. Deve ser observado que a rede Facebook coloca as ações Curtir, Comentar e Compartilhar nessa ordem, da esquerda para a direita, assim que é feita uma publicação, entretanto, os usuários podem escolher a ordem de execução.

Considerando a execução ou não das ações Curtir, Comentar e Compartilhar como um elemento de uma lista, diferentes listas ordenadas podem ser extraídas de uma base de dados

\footnotetext{
${ }^{4}$ https://www.python.org/

${ }^{5} \mathrm{https}: / /$ www.mysql.com/
} 
que contém tais elementos. Por exemplo, uma publicação que só tem curtidas pode ser representada pela lista $\langle\mathrm{L}\rangle$, uma publicação que só tem comentários e compartilhamentos pode ser representada pela lista $<\mathrm{K}, \mathrm{S}\rangle$, e assim por diante.

Originalmente, o GSP não manipula valores numéricos e para que um valor faça parte de uma sequência, é necessário atender um limiar (frequência mínima) arbitrado pelo usuário. Na implementação aqui realizada, suporte mínimo considerado para extração de sequências de ações foi $\alpha \geq 0$, portanto, todas as sequências que constam na base de dados devem ser extraídas. São geradas sequências de tamanho 1 até as de tamanho igual ao número de atributos (colunas) da base, sem valores de atributos repetidos.

Assim que é gerada uma sequência, seu número de ocorrência é determinado percorrendo-se toda base de dados. Cada linha da base tem dados referentes a uma interação social. A partir do número de ocorrência, a frequência de cada sequência é obtida como percentual do total de interações sociais presentes na base. Na Figura 1, a extração dos padrões sequenciais e as respectivas frequências, estão no passo 3.

\subsection{Validação do Aprendizado}

A validação do aprendizado dos padrões sequenciais de ações é feita a partir do confronto do número de ocorrência das sequências aprendidas com contagens retornadas por consultas feitas em Linguagem de Consulta Estruturada - $\mathrm{SQL}^{6}$. O passo de validação da extração das sequências e suas respectivas frequência de ocorrência está apresentado no passo 4 na Figura 1. Na Listagem 1 é apresentado o mapeamento da sequência $<\mathrm{LKS}>$ na sua respectiva consulta $\mathrm{SQL}$. Nessas consultas, são realizadas contagens iguais a 0 ou diferentes de 0 de cada ação.

$<\mathbf{L K S}>$

SELECT COUNT(*) FROM 'posts' WHERE status_type IS NOT NULL

AND num_likes $<>0$ AND num_comments $<>0$ AND num_shares $<>0$

$<\mathbf{L} ! \mathbf{K S}>$

SELECT COUNT(*) FROM 'posts ' WHERE status_type IS NOT NULL AND num_likes $<>0$ AND num_comments $==0$ AND num_shares $<>0$

$<\mathbf{L} ! \mathbf{K} ! \mathbf{S}>$

SELECT COUNT(*) FROM 'posts' WHERE status_type IS NOT NULL AND num_likes $<>0$ AND num_comments $==0$ AND num_shares $==0$

$<! \mathbf{L} ! \mathbf{K} ! \mathbf{S}>$

SELECT COUNT(*) FROM 'posts' WHERE status_type IS NOT NULL AND num_likes $==0$ AND num_comments $==0$ AND num_shares $==0$

Listagem 1. Exemplos de consultas em SQL

Considerando que as ações analisadas são Curtir, Comentar e Compartilhar, dessa forma, são feitas contagens do número de curtidas, do número de comentários e do número de compartilhamentos iguais a 0 ou diferentes de 0 . Havendo coincidência entre o número de ocorrência de cada sequência, obtidas a partir do aprendizado via GSP, e a contagem retornada pelas consultas SQL, esses resultados são considerados

\footnotetext{
${ }^{6} \mathrm{https} / / / \mathrm{www}$. oracle.com/br/database/technologies/appdev/sql.html
}

válidos. Em suma, os resultados são válidos se houver coincidência entre o número de ocorrência do que foi aprendido via GSP com a contagem do que foi consultado via SQL.

\subsection{Cômputo do Capital Social Bourdieusiano}

Dentro de uma RSO, o Capital Social Bourdieusiano é um tipo de capital social digital que emerge da estrutura das conexões sociais digitais e das interações sociais online [6] [7]. Portanto, o Capital Social Bourdieusiano é baseado em interações sociais que ocorrem a partir do reconhecimento mútuo e das trocas materiais e/ou simbólicas (grafo de interação [29] [30]), que são realizados entre indivíduos que fazem parte de uma rede de relacionamentos(grafo social [29] [30]). O Capital Social Bourdieusiano independe de outras formas de capital (econômico, cultural ou simbólico), porém, é altamente dependente das trocas materiais e/ou simbólicas que instituem o reconhecimento mútuo entre indivíduos que fazem parte de uma rede de relacionamentos [4] [7].

Nesta pesquisa, considera-se que o reconhecimento mútuo e as trocas simbólicas se cristalizam dentro da rede Facebook a partir da execução ou não das ações Curtir, Comentar e Compartilhar. Essas trocas estão retratadas nas sequências de ações extraídas via GSP. Não há trocas materiais dentro de uma rede digital. Bourdieu [4] destaca que a manutenção e expansão do volume de Capital Social acumulado por um agente é resultante do seu esforço incessante de sociabilidade, ou seja,é resultante do equilíbrio entre a) a sua capacidade de mobilização efetiva, b) o número interações sociais provocadas pelo agente e c) do tamanho da sua rede de conexões.

Em um trabalho anterior [10], foi apresentado que a capacidade de mobilização está associada com as frequências de ocorrência das sequências que apresentam no seu corpo a execução de uma ou mais ações Curtir, Comentar e Compartilhar. Em contraste, a incapacidade de mobilização está associada com a frequência de ocorrência de uma sequência que apresenta no seu corpo a não execução de nenhuma das ações Curtir, Comentar e Compartilhar.

No presente estudo, a capacidade de mobilização efetiva é medida a partir da aplicação de um conjunto de pesos nas frequências de ocorrência das sequências. Os pesos correspondem ao número de ações efetivamente a executadas que constam do corpo de uma sequência. Sendo assim, quanto mais ações executadas, mais efetiva é a capacidade do agente mobilizar seus seguidores. A capacidade de mobilização efetiva é formalizada na Equação 1.

$$
\text { Mob.Ef. }=\frac{\sum_{i=1}^{n} i * \operatorname{freq}(\text { i.acoes })}{\sum_{i=1}^{n} i}
$$

na qual:

Mob.Ef. = capacidade de mobilização efetiva i = número de ações executadas

freq(i.acoes) = frequência de ocorrência das sequências com i ações executadas 
Tabela 1. Exemplo de Conversão de Bases de Dados numéricas em não-numéricas

\begin{tabular}{|c|c|c|c|c|c|c|c|c|c|c|c|c|c|c|c|c|c|}
\hline \multicolumn{9}{|c|}{ a) Bases de Dados numéricas } & \multicolumn{9}{|c|}{ b) Bases de Dados não-numéricas } \\
\hline \multicolumn{3}{|c|}{ Base 1} & \multicolumn{3}{|c|}{ Base 2} & \multicolumn{3}{|c|}{ Base 3} & \multicolumn{3}{|c|}{ Base 1} & \multicolumn{3}{|c|}{ Base 2} & \multicolumn{3}{|c|}{ Base 3} \\
\hline 4 & 2 & 10 & 3 & 2 & 0 & 3 & 4 & 0 & $L$ & $K$ & $S$ & $L$ & $K$ & $! S$ & $L$ & $K$ & $! S$ \\
\hline 3 & 18 & 0 & 0 & 0 & 0 & 0 & 8 & 0 & $L$ & $K$ & $! S$ & $! L$ & $! K$ & $! S$ & $! L$ & $K$ & $! S$ \\
\hline 0 & 2 & 8 & 0 & 2 & 0 & 0 & 3 & 2 & $! L$ & $K$ & $S$ & $! L$ & $K$ & !S & $! L$ & $K$ & $S$ \\
\hline 0 & 6 & 0 & 10 & 5 & 2 & 2 & 5 & 3 & $! L$ & $K$ & $! S$ & $L$ & $K$ & $S$ & $L$ & $K$ & $S$ \\
\hline 19 & 0 & 0 & 0 & 3 & 3 & 0 & 0 & 0 & $L$ & $! K$ & $! S$ & $! L$ & $K$ & $S$ & $! L$ & $! K$ & $! S$ \\
\hline 0 & 0 & 0 & 0 & 5 & 1 & 0 & 17 & 11 & $! L$ & $! K$ & $! S$ & $! L$ & $K$ & $S$ & $! L$ & $K$ & $S$ \\
\hline
\end{tabular}

Tabela 2. Exemplo de Validação de Resultados - Câmpus GYM

\begin{tabular}{|c||c|c|c|c|c|c|c|c|c|}
\hline GYM & $!$ K!L!S & $! K L ! S$ & K!L!S & !K!LS & LK!S & !KLS & K!LS & KLS & total \\
\hline GSP & 150 & 729 & 8 & 22 & 182 & 973 & 2 & 1.108 & 3.174 \\
\hline SQL & 150 & 729 & 8 & 22 & 182 & 973 & 2 & 1.108 & 3.174 \\
\hline$\neq$ & 0 & 0 & 0 & 0 & 0 & 0 & 0 & 0 & 0 \\
\hline
\end{tabular}

Tabela 3. Exemplo de Validação de Resultados - Câmpus TRD

\begin{tabular}{|c||c|c|c|c|c|c|c|c|c|}
\hline TRD & !K!L!S & !KL!S & K!L!S & !K!LS & LK!S & !KLS & K!LS & KLS & total \\
\hline GSP & 8 & 292 & 0 & 1 & 108 & 304 & 0 & 325 & 1038 \\
\hline SQL & 8 & 292 & 0 & 1 & 108 & 304 & 0 & 325 & 1038 \\
\hline$\neq$ & 0 & 0 & 0 & 0 & 0 & 0 & 0 & 0 & 0 \\
\hline
\end{tabular}

A adoção dos pesos caracteriza a participação dos indivíduos dentro do grupo (Página Institucional) pois, quanto mais ações executadas (trocas), maior o reconhecimento existente entre uma fanpage e seus seguidores. Sendo assim, os pesos promovem um desbalanceamento em favor de uma participação no grupo com mais execução de ações. Foi construída uma equação para formalizar a medida da capacidade de mobilização efetiva. Em trabalhos futuros, valores como a média de curtidas, a média de comentários e a média de compartilhamentos poderão ser usados como pesos para caracterizar a participação dentro do grupo.

Considera-se que o esforço incessante de sociabilidade está associado ao equilíbrio entre a capacidade efetiva de mobilização, o número de interações sociais que são extraídas de cada Página Institucional e o tamanho da rede de relacionamentos (número de seguidores) que o agente possui. Dessa forma, a medida da capacidade de mobilização efetiva é usada como um multiplicador do número de interações sociais, e ainda, do número de seguidores. Como resultado, a soma dessas multiplicações representa o volume de Capital Social Bourdieusiano acumulado em uma Página Institucional. A Equação 2 foi construída, neste trabalho, para formalizar a medida do volume de Capital Social Bourdieusiano acumulado em Páginas Institucionais.

$$
\nu C S B=(M o b . E f . * \# I S)+(M o b \cdot E f . * \# s e g)
$$

na qual:

vCSB = volume de Capital Social Bourdieusiano

Mob.Ef. = capacidade de mobilização efetiva

\#IS = número de interações sociais

\#seg = número de seguidores

O passo de cômputo do Capital Social Bourdieusiano está apresentado em 5 na Figura 1. Em trabalhos futuros, pretende- se considerar a polaridade do sentimento contido na publicação e nos comentários feitos em seguida e, a partir desses sentimentos, determinar se uma interação é positiva, negativa ou neutra. Outro aprimoramento a ser feito é relacionar o número de usuários ativos (que participam efetivamente das interações sociais a partir da execução de ações) com o número de seguidores, e utilizar essa relação como fator de ponderação do tamanho da rede.

\section{Validação da Abordagem}

Foi elaborado um experimento com o objetivo de validar a abordagem de apuração do CSB aqui proposta, no qual foram analisadas 27 Páginas Institucionais da rede Facebook. Em seguida, os resultados obtidos com a experimentação são discutidos à luz da Teoria de Bourdieu com foco na compreensão da composição do CSB de cada instituição.

Foram selecionadas duas instituições federais de ensino que seguem diretrizes do governo federal brasileiro $^{7}$ para regular a atividade dessas instituições dentro das RSO. A primeira instituição tem 14 campi, e a segunda, tem 13. Cada campi tem sua página.

Nessas diretrizes há, por exemplo, restrições expressas quanto a adoção de medidas que provoquem o aumento nãoorgânico do número de seguidores dos perfis. Há recomendações para que sejam evitadas publicações com conteúdo considerado ofensivo, conteúdo controverso que possa provocar algum tipo de polêmica, e ainda, conteúdo cuja fonte não possa ser averiguada ou que possa ser potencialmente enquadrado como notícia falsa (fake news). Além disso, cada perfil é sempre o único provedor de estímulos sociais, nãoseguidores e seguidores podem interagir somente executando as ações Comentar, Curtir e Compartilhar. Acredita-se que,

\footnotetext{
${ }^{7}$ www.governodigital.gov.br/transformacao/compras/orientacoes/orientacoesredes-sociais-1
} 
um não-seguidor que comenta, curte ou compartilha algum conteúdo, dificilmente não se torna seguidor.

\subsection{Bases de dados e ETL}

Como resultado das fases de identificação e coleta dos dados foram construídas 27 bases de dados, uma para cada Página Institucional. Nessas bases foram armazenadas informações como nome da página, identificador da página, identificador da postagem, conteúdo da postagem, tipo de mídia publicada na mensagem, data e hora da publicação, número de curtidas, número de comentários, número de compartilhamentos (internos). A partir de cada uma dessas bases, foi construída outra base de dados contendo apenas número de curtidas, número de comentários e número de compartilhamentos, ou seja, foram construídas 27 bases de dados numéricas. Na Tabela 1a são apresentados exemplos de como os dados estão organizados nessas bases de dados numéricas.

$\mathrm{Na}$ transformação dos dados, valores numéricos foram transformados em valores não-numéricos. O número de curtidas maior que 0 é representado por $L$ e valores iguais a 0 por !L. O número de comentários maior que 0 é representado por $K$ e valores iguais a 0 por $! K$. O número de compartilhamentos maior que 0 por $S$ e valores iguais a 0 por $! S$.

Os dados transformados foram carregados em outra base com valores não-numéricos, ou seja, para cada base de dados coletados da RSO, foi criada uma (nova) base de dados nãonuméricos. A partir de cada base de dados não-numéricos foi realizado o aprendizado de sequência de ações. Foram utilizados dados de um total de 20.093 interações sociais capturadas. Um exemplo de como os dados estão organizados nas bases não-numéricas é apresentado na Tabela $1 \mathrm{~b}$.

Nesse processo de transformação de valores numéricos em não-numéricos há perda de informação. Para contornar esse problema, no presente estudo, são mantidas tanto as 27 bases numéricas quanto as 27 bases não-numéricas para confronto de informação. Em trabalhos futuros, valores como a média de curtidas, a média de comentários e a média de compartilhamentos poderão ser usadas como pesos para caracterizar a participação dos seguidores dentro de cada Página Institucional. Essa estratégia pode minimizar os efeitos da perda de informação na transformação dos dados e poderá ser incorporada na abordagem como desdobramento e aprimoramento das contribuições da presente pesquisa.

\subsection{Sequências de Ações e Validação}

A seguir, na Listagem 4, são apresentadas exemplos das sequências de ações extraídas automaticamente de cada base de dados não-numéricos.

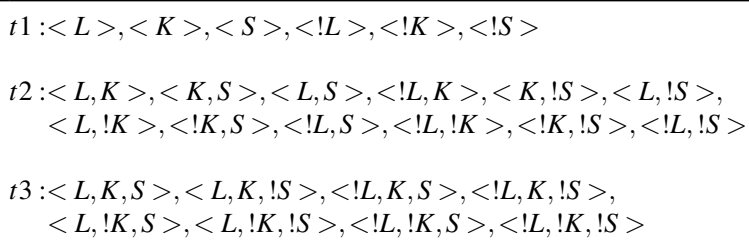

Listagem 2. Exemplo de Sequências de Ações
Foram extraídas sequências de tamanho $1(t 1)$, tamanho $2(t 2)$ e tamanho $3(t 3)$. O somatório do número de ocorrências das sequências de tamanho 1 cor- responde ao total de interações sociais capturadas de cada página. Da mesma forma, o somatório do número de ocorrências das sequências de tamanho 2, e ainda, o somatório do número de ocorrências das sequências de tamanho 3.

$\mathrm{Na}$ Listagem 4, a sequência $<\mathrm{L}, \mathrm{K}, \mathrm{S}>$ retrata a execução das 3 ações Curtir, Comentar e Compartilhar. As sequências $<\mathrm{L}, \mathrm{K}$, !S $>,<$ !L, K,S $>,<\mathrm{L}$, !K,S $>$ retratam a execução de 2 dentre as ações Curtir, Comentar e Compartilhar. As sequências $<$ !L, K,!S $>,<\mathrm{L}$, !K,! $>,<$ !L,!K,S $>$ retratam a execução de 1 dentre as ações Curtir, Comentar e Compartilhar. A sequência $<! \mathrm{L}, ! \mathrm{K}, ! \mathrm{S}>$ retrata a execução de 0 ações.

A efetiva capacidade de mobilização está associada com as sequências que contém ações executadas no seu corpo, portanto, com sequências que retratam a execução de 3,2 e 1 ações Curtir, Comentar e Compartilhar. A sequência $<$ !L,!K,!S $>$ está associada com a incapacidade de mobilização, pois nenhuma ação foi executada.

Na Tabela 2 é apresentado o resultado da validação dos valores obtidos a partir da análise dos dados capturados da página do Câmpus GYM. Na Tabela 3 é apresentado o resultado da validação dos valores obtidos a partir da análise dos dados capturados da página do Câmpus TRD.

Em ambas as tabelas, na segunda linha estão os números de ocorrência obtidos via GSP, e na terceira linha, os resultados das contagens feitas via consulta SQL. Para cada página foi construída uma tabela de validação.

Os resultados foram considerados válidos, pois o número de ocorrência das sequências aprendidas pelo algoritmo GSP, a partir dos dados constantes na base da Página Institucional TRD, coincidiram com os valores retornados pelas consultas SQL, também feita na base TRD, sendo assim, nenhum dado ficou de fora da análise. Foram construídas tabelas de validação dos resultados igual as Tabelas 2 e 2 para validar cada sequência aprendida, em cada base de dados não-numérica.

Os resultados obtidos para o número de ocorrência das sequências de ações extraídas automaticamente de cada base de dados não-numéricos foram considerados válidos. Havendo alguma diferença entre os números de ocorrência obtidos via GSP e os resultados das contagens feitas via consulta SQL, é necessário verificar qual interação social ficou de fora da análise, ou foi contada em duplicidade, e corrigir o problema.

\subsection{Apuração do Capital Social Bourdieusiano}

Nas Tabelas 4 e 5 são apresentados um síntese da apuração das frequências de ocorrência de cada sequência aprendida, a apuração da capacidade de mobilização que cada agente Página Institucional possui, a apuração da capacidade de mobilização efetiva, o número de interações capturadas de cada fanpage e analisadas para obtenção das frequências, o número de seguidores e o volume de Capital Social Bourdieusiano acumulado. A identificação de cada Página Institucional é apresentada na coluna 1 de ambas as tabelas. 
Bourdieusian Social Capital within Institutional Pages and Profiles

Tabela 4. Apuração do Capital Social Bourdieusiano IFG

\begin{tabular}{|c|c|c|c|c|c|c|c|c|c|c|}
\hline & 1 & 2 & 3 & 4 & 5 & 6 & 7 & 8 & 9 & 10 \\
\hline 0 & ID & 0 ação & 1 ação & 2 ações & 3 ações & Mob. & Mob.Ef. & \#IS & \#seg. & vCSB \\
\hline 1 & GYM & $4,73 \%$ & $23,91 \%$ & $36,45 \%$ & $34,91 \%$ & $95,27 \%$ & $33,59 \%$ & 3.174 & 11.711 & $4.999,97$ \\
\hline 2 & ITU & $17,93 \%$ & $30,50 \%$ & $32,45 \%$ & $19,11 \%$ & $82,07 \%$ & $25,46 \%$ & 3.223 & 4.249 & $1.902,20$ \\
\hline 3 & APA & $10,98 \%$ & $33,45 \%$ & $36,55 \%$ & $19,03 \%$ & $89,02 \%$ & $27,27 \%$ & 2.386 & 4.190 & $1.793,29$ \\
\hline 4 & ANA & $12,97 \%$ & $36,75 \%$ & $36,68 \%$ & $13,60 \%$ & $87,03 \%$ & $25,15 \%$ & 1.426 & 2.919 & $1.092,85$ \\
\hline 5 & LUZ & $19,97 \%$ & $40,09 \%$ & $27,24 \%$ & $12,69 \%$ & $80,03 \%$ & $22,11 \%$ & 1.292 & 3.292 & $1.013,54$ \\
\hline 6 & FRM & $23,03 \%$ & $38,91 \%$ & $27,02 \%$ & $11,04 \%$ & $76,97 \%$ & $21,01 \%$ & 1.984 & 2.557 & 954,05 \\
\hline 7 & CGO & $19,10 \%$ & $47,47 \%$ & $25,20 \%$ & $8,23 \%$ & $80,90 \%$ & $20,43 \%$ & 1.361 & 3.007 & 892,21 \\
\hline 8 & VAL & $7,54 \%$ & $29,76 \%$ & $41,12 \%$ & $21,58 \%$ & $92,46 \%$ & $29,46 \%$ & 783 & 2.199 & 878,48 \\
\hline 9 & GYO & $14,71 \%$ & $42,26 \%$ & $29,98 \%$ & $13,05 \%$ & $85,29 \%$ & $23,56 \%$ & 1.441 & 2.258 & 871,49 \\
\hline 10 & JTI & $21,78 \%$ & $44,91 \%$ & $25,77 \%$ & $7,54 \%$ & $78,22 \%$ & $19,85 \%$ & 1.405 & 2.965 & 867,26 \\
\hline 11 & AGL & $5,93 \%$ & $43,18 \%$ & $50,89 \%$ & $0,00 \%$ & $94,07 \%$ & $24,16 \%$ & 674 & 2.042 & 656,17 \\
\hline 12 & SCA & $7,14 \%$ & $54,03 \%$ & $27,53 \%$ & $11,30 \%$ & $92,86 \%$ & $23,83 \%$ & 770 & 1.734 & 596,73 \\
\hline 13 & URU & $50,05 \%$ & $23,79 \%$ & $21,03 \%$ & $5,13 \%$ & $49,95 \%$ & $13,54 \%$ & 975 & 3.043 & 543,98 \\
\hline 14 & INH & $0,00 \%$ & $0,00 \%$ & $100,00 \%$ & $0,00 \%$ & $100,00 \%$ & $33,33 \%$ & 2 & 278 & 93,33 \\
\hline
\end{tabular}

Tabela 5. Apuração do Capital Social Bourdieusiano IFGoiano

\begin{tabular}{|c|c|c|c|c|c|c|c|c|c|c|}
\hline & 1 & 2 & 3 & 4 & 5 & 6 & 7 & 8 & 9 & 10 \\
\hline 0 & ID & 0 ação & 1 ação & 2 ações & 3 ações & Mob. & Mob.Ef. & \#IS & \#seg. & vCSB \\
\hline 1 & URT & $5,06 \%$ & $30,43 \%$ & $44,01 \%$ & $20,51 \%$ & $94,94 \%$ & $29,99 \%$ & 1.068 & 9.638 & $3.211,13$ \\
\hline 2 & RVD & $8,64 \%$ & $53,09 \%$ & $29,63 \%$ & $8,64 \%$ & $91,36 \%$ & $23,05 \%$ & 81 & 10.293 & $2.390,72$ \\
\hline 3 & MOR & $40,27 \%$ & $15,49 \%$ & $28,24 \%$ & $16,00 \%$ & $59,73 \%$ & $20,00 \%$ & 1.356 & 8.819 & $2.034,75$ \\
\hline 4 & TRD & $0,77 \%$ & $28,23 \%$ & $39,69 \%$ & $31,31 \%$ & $99,23 \%$ & $33,59 \%$ & 1.038 & 4.967 & $2.017,09$ \\
\hline 5 & IPO & $3,44 \%$ & $23,37 \%$ & $41,49 \%$ & $26,27 \%$ & $91,12 \%$ & $30,86 \%$ & 552 & 4.086 & $1.431,17$ \\
\hline 6 & CPB & $2,17 \%$ & $40,68 \%$ & $39,27 \%$ & $17,89 \%$ & $97,83 \%$ & $28,81 \%$ & 1.062 & 3.679 & $1.366,05$ \\
\hline 7 & CER & $5,06 \%$ & $35,14 \%$ & $37,56 \%$ & $22,24 \%$ & $94,94 \%$ & $29,50 \%$ & 1.403 & 2.905 & $1.270,70$ \\
\hline 8 & CAT & $2,39 \%$ & $31,52 \%$ & $38,04 \%$ & $28,04 \%$ & $97,61 \%$ & $31,96 \%$ & 460 & 2.921 & $1.080,45$ \\
\hline 9 & PSS & $1,36 \%$ & $49,05 \%$ & $34,15 \%$ & $15,45 \%$ & $98,64 \%$ & $27,28 \%$ & 369 & 2.836 & 874,35 \\
\hline 10 & HID & $1,57 \%$ & $39,22 \%$ & $41,96 \%$ & $17,25 \%$ & $98,43 \%$ & $29,15 \%$ & 255 & 1.982 & 652,09 \\
\hline 11 & CRI & $3,37 \%$ & $35,39 \%$ & $41,01 \%$ & $20,22 \%$ & $96,63 \%$ & $29,68 \%$ & 356 & 1.586 & 576,42 \\
\hline 12 & POI & $0,00 \%$ & $31,51 \%$ & $52,74 \%$ & $15,75 \%$ & $100,00 \%$ & $30,71 \%$ & 146 & 764 & 279,44 \\
\hline 13 & IPA & $21,57 \%$ & $23,53 \%$ & $50,98 \%$ & $3,92 \%$ & $78,43 \%$ & $22,88 \%$ & 51 & 542 & 135,65 \\
\hline
\end{tabular}

Nas Tabelas 4 e 5, a frequência de ocorrência da sequência com 0 ação executada é apresentada na coluna 2 e correspondente a frequência de ocorrência da sequência $<! \mathrm{L} ! \mathrm{K} ! \mathrm{S}>$. $\mathrm{Na}$ coluna 3 é apresentada a frequência de ocorrência das sequências com 1 ação executada, cujo percentual é calculado a partir da soma das frequências de ocorrência das sequências $<\mathrm{L}$ !K!S $>,<$ !LK!S $>$ e $<$ !L!KS $>$. Na coluna 4 é apresentada a frequência de ocorrência das sequências com 2 ações executadas, cujo percentual é calculado a partir da soma das frequências de ocorrência das sequências $<$ LK!S $>,<$ !KLS $>$ e $<$ K!LS $>$. Na coluna 5 é apresentada a frequência de ocorrência da sequência com 3 ações executadas, que corresponde a frequência de ocorrência da sequência $<$ KLS $>$.

Ainda nas Tabelas 4 e 5, na coluna 6 (Mob.) é apresentado o resultado da apuração da capacidade de mobilização, cujo valor é obtido a partir da soma das colunas 3,4 e 5 . Na coluna 7 é apresentado o resultado da apuração da capacidade de mobilização efetiva (Mob.Ef.), cujo valor é obtido a partir da média ponderada dos valores das colunas 3 , 4 e 5 onde os pesos são o número de ações executadas.

Seguindo nas Tabelas 4 e 5, na coluna 8 é apresentado o número de interações sociais capturadas. Na coluna 9 é apresentado o número de seguidores (tamanho da rede de conexões). Na coluna 10 é apresentado o valor apurado para o volume de Capital Social Bourdieusiano acumulado em cada página. Os resultados apresentados em ambas as tabelas estão ordenados pelos valores da coluna 10 (vCSB) em ordem decrescente. Na Seção seguinte, os resulados apurados do volume de CSB são discutidos em comparação com a capacidade de mobilização efetiva (coluna 7), número de seguidores (coluna 9) e número de interações sociais (coluna 8).

\subsection{Discussão dos Resultados do Experimento}

Nesta Seção os resultados apresentados nas Tabelas 4 e 5 são discutidos em termos do seu alinhamento com as teorias de Bourdieu, no que se refere ao sistema de trocas e reconhecimento mútuo, capacidade de mobilização efetiva e, por fim, composição, manutenção e crescimento do volume de Capital Social acumulado que estão associados ao esforço incessante de sociabilidade do agente.

\subsubsection{Representação do sistema de trocas simbólicas e do reconhecimento mútuo}

Para computar o CSB, apenas as sequências de ações de tamanho 3 foram consideradas, pois essas sequências retratam no seu corpo uma associação entre a execução e/ou não das ações Curtir, Comentar e Compartilhar. Essas sequências de ações são representações que estão alinhadas com as teorias de Bourdieu no que refere à representação do sistema de trocas e reconhecimento mútuo entre um agente e sua rede de conexões. Em trabalhos futuros, as sequências de tamanho 1 
(a) IFG - Mobilização Efetiva x Interações Sociais

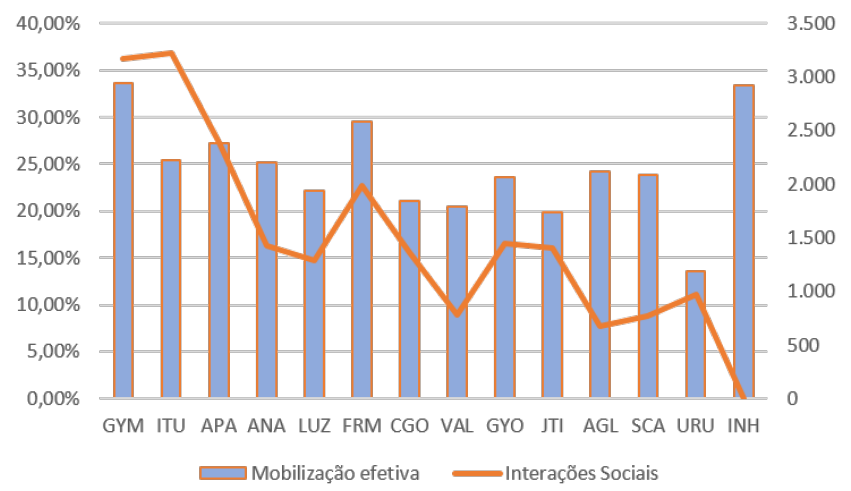

(b) IFGoiano - Mobilização Efetiva x Interações Sociais

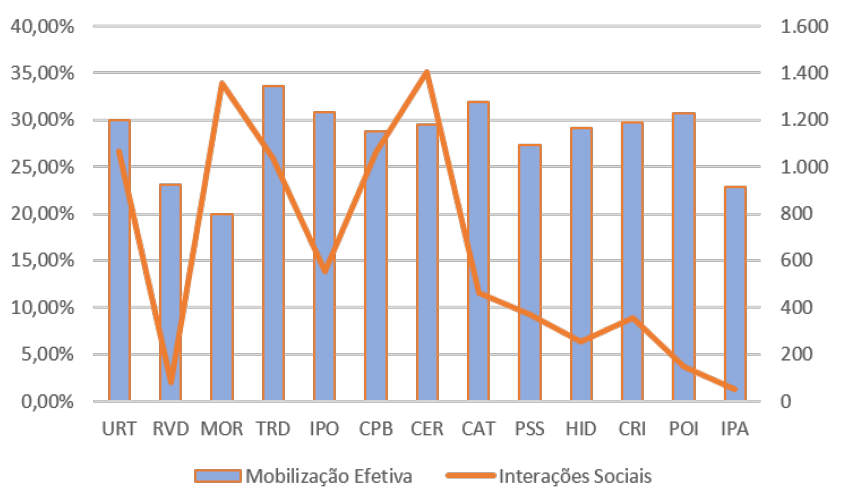

Figura 2. Capacidade de Mobilização Efetiva x Interações Sociais

(a) IFG - Mobilização Efetiva x Seguidores

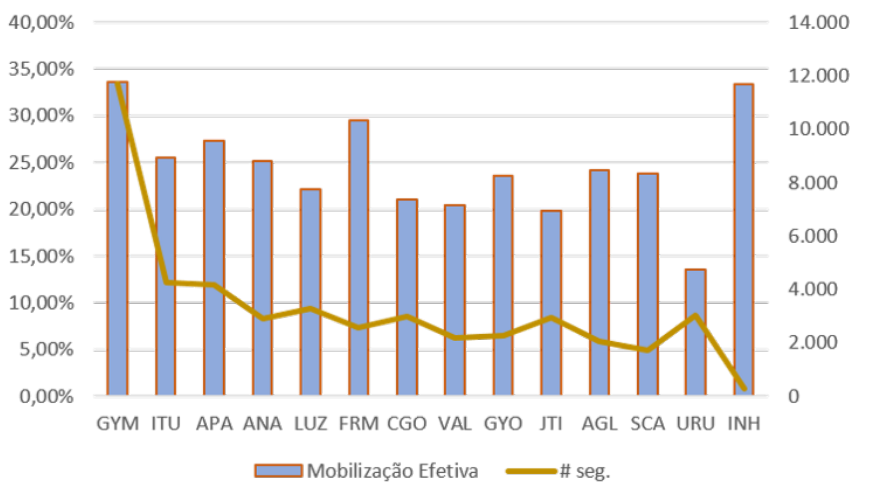

(b) IFGoiano - Mobilização Efetiva x Seguidores

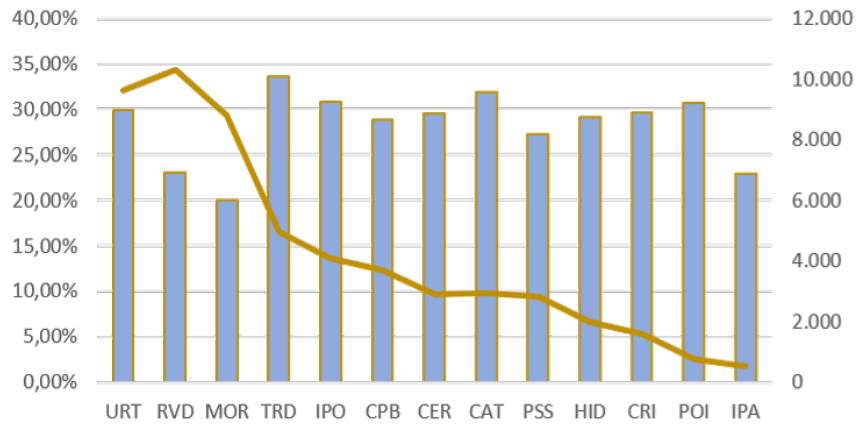

$\square$ Mobilização Efetiva — \# seg.

Figura 3. Capacidade de Mobilização Efetiva x Seguidores

e 2 poderão ser consideradas em outras análises.

\subsubsection{Capacidade de mobilização efetiva e a não propor- cionalidade com o número de interações sociais}

Na Figura 2 é apresentada uma comparação entre a capacidade de mobilização efetiva e o número de interações sociais. Nas Tabelas 4 e 5, os valores da capacidade de mobilização efetiva estão na coluna 7 (Mob.Ef.) e o número de interações sociais na coluna 8 (\#IS.). A Figura 2a apresenta os resultados apurados para cada Página Institucional do IFG. A Figura 2b apresenta os resultados para cada Página do IFGoiano.

$\mathrm{Na}$ Figura 2a, a Página Institucional ITU tem o maior número de interações sociais e uma capacidade de mobilização efetiva que não é a maior dentre as demais. Deve ser observado que as páginas GYM e INH possuem as maiores capacidades de mobilização efetiva, entretanto, GYM tem um dos maiores números de interações sociais e INH tem o menor número de interações sociais.

Na Figura 2b, a Página Institucional MOR tem capacidade de mobilização efetiva menor que todas demais páginas e o segundo maior número de interações sociais. A Página Institucional TRD tem a maior capacidade de mobilização efetiva dentre as páginas do IFGoiano.
Os resultados apresentados na Figura 2 mostram que a capacidade de mobilização efetiva não tem relação de proporcionalidade com o número de interações sociais. Pode ser observado, por exemplo, na Tabela 4, que a página INH tem apenas 2 interações sociais (coluna 8), porém, ao fazer essas publicações, ela consegue mobilizar sua rede de contatos em todas essas interações com a execução de 2 ações (coluna 4). Sendo assim, é possível notar que os resultados produzidos pela medida de capacidade de mobilização efetiva não é proporcional ao número de interações sociais.

\subsubsection{Capacidade de mobilização efetiva do agente inde- pende do tamanho da rede de conexões}

Na Figura 3 é apresentada uma comparação entre a capacidade de mobilização efetiva e o número de seguidores. Nas Tabelas 4 e 5, os valores da capacidade de mobilização efetiva são apresentados na coluna 7 (Mob.Ef.) e o número de seguidores na coluna 9 (\#seg.). A Figura 3a apresenta os resultados apurados para cada Página Institucional do IFG. A Figura $3 \mathrm{~b}$ apresenta os resultados apurados para cada Página Institucional do IFGoiano.

Na Figura 3a apenas a Página Institucional identificada como GYM tem uma grande rede de relacionamentos e uma 
(a) IFG - Mobilização Efetiva x vCSB

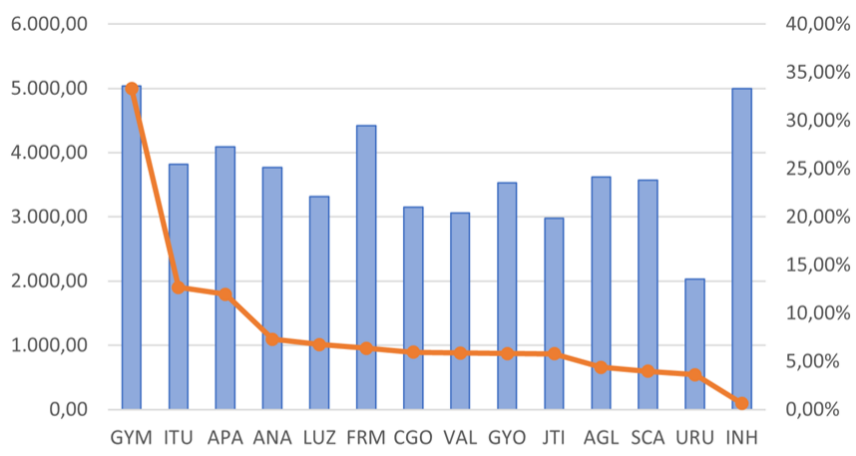

$\square$ Mobilização Efetiva $\longrightarrow v$ CSB (b) IFGoiano - Mobilização Efetiva x vCSB

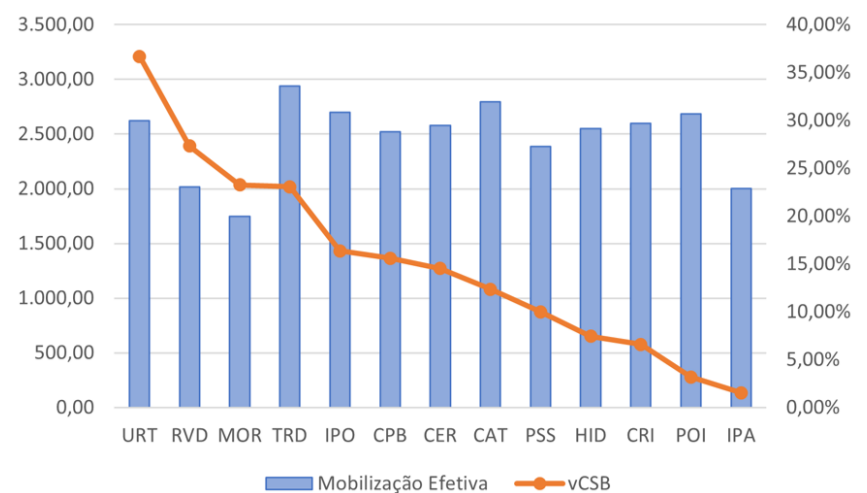

Figura 4. Mobilização Efetiva x Capital Social Bourdieusiano

(a) IFG - Mobilização x Seguidores x Int. Sociais x vCSB

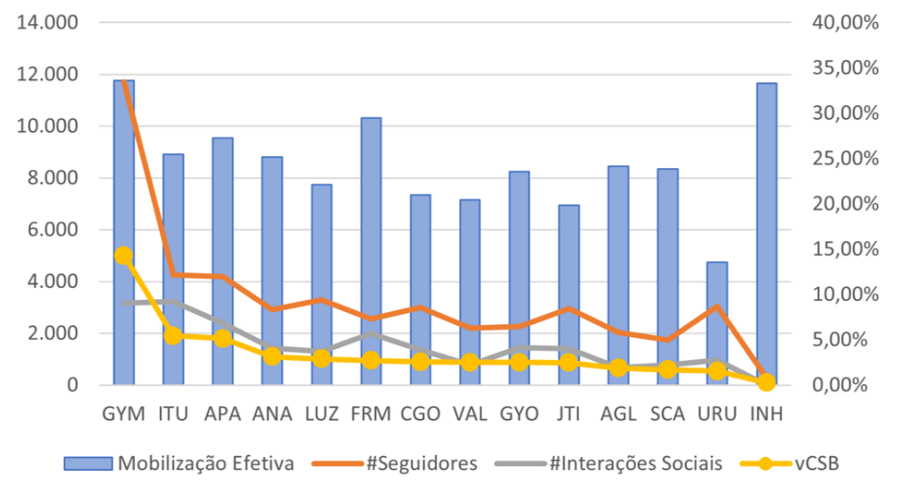

(b) IFGoiano - Mobilização x Seguidores x Int. Sociais x vCSB

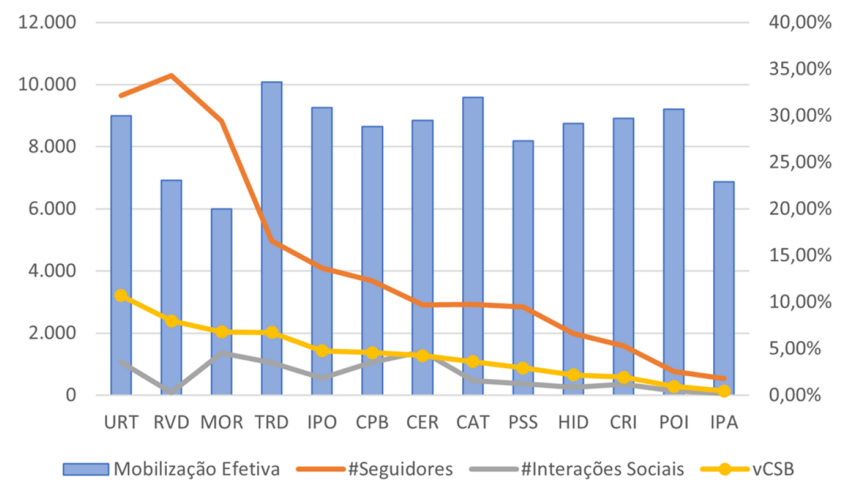

Figura 5. Mobilização Efetiva x Seguidores x Interações Sociais x Capital Social Bourdieusiano

grande capacidade de mobilização efetiva. As demais Páginas Institucionais do IFG não têm essa proporcionalidade. $\mathrm{Na}$ Figura 3b, as Páginas Institucionais URT, RVD e MOR tem capacidade de mobilização efetiva menor que seus respectivos números de seguidores. As demais Páginas Institucionais do IFGoiano têm capacidade de mobilização efetiva maior que seus respectivos números de seguidores.

Bourdieu [4] menciona que a capacidade de mobilização efetiva do agente independe do tamanho da sua rede de conexões, ou seja, uma grande rede não garante uma grande capacidade de mobilização efetiva. É possível notar que os resultados produzidos pela medida de capacidade de mobilização efetiva, apresentados na Figura 3, não são proporcionais do número de seguidores.

Nas Figura 2 e 3 é possível observar que a medida de capacidade de mobilização efetiva produz resultados que não são proporcionais nem ao número de interações sociais nem ao do número de seguidores. Portanto, os resultados estão ali- nhados com a teoria de Bourdieu no que refere à independência da capacidade de mobilização efetiva do número de interações sociais e do tamanho da rede do agente.

A aplicação de um conjunto de pesos nas frequências de ocorrência das sequências, que correspondem ao número de ações efetivamente a executadas no corpo de cada uma delas, permitem que a medida de capacidade de mobilização efetiva, apresentada na Equação 1, produza resultados alinhados com as teorias de Bourdieu.

Esses resultados permitem identificar a capacidade que um agente de estimular sua rede de relacionamentos a realizarem trocas e se reconhecerem mutuamente, privilegiando trocas e reconhecimentos nos quais há mais funcionalidades (ações) são executadas pelos seguidores.

\subsubsection{Capacidade de mobilização efetiva não é conver- tida automaticamente em vCSB}

Na Figura 4 é apresentada uma comparação entre a capacidade de mobilização efetiva e o volume de CSB apurado. Nas Tabelas 4 e 5, os valores da capacidade de mobilização efetiva estão na coluna 7 (Mob.Ef.) e o número de seguidores na coluna 10 (vCSB.). A Figura 4a apresenta os resultados apurados para cada Página Institucional do IFG. A Figura 4b apresenta os resultados para cada Página do IFGoiano.

Os resultados apresentados na Figura 4 permitem observar que a capacidade de mobilização efetiva não é convertida automaticamente em Capital Social Bourdieusiano. Apenas a Página Institucional identificada como GYM, na Figura 4a, possui vCSB proporcional a capacidade de mobilização efe- 
tiva. Na Figura 4b, nenhuma Página Institucional tem vCSB proporcional a capacidade de mobilização efetiva.

Esses resultados indicam que a capacidade de mobilização efetiva precisa ser equilibrada com o número de interações sociais e o número de seguidores, para que seja possível compreender a conversão do esforço de sociabilidade em vCSB.

\subsubsection{A manutenção e expansão do CSB pressupõe um esforço incessante de sociabilidade}

Bourdieu [4] também destaca que a manutenção e o crescimento do Capital Social dependem de um esforço incessante de sociabilidade do agente em estimular as trocas e o reconhecimento mútuo na sua rede de conexões.

No caso das RSO, esse é um esforço um esforço contínuo para manter e aumentar a) o número de interações sociais entre o agente e seus seguidores, com a correspondente resposta dos seguidores para realizar o maior número de ações possível; b) a rede de conexões de forma orgânica, ou seja, mantendo e aumentando o número de seguidores que interagem entre si.

Isso significa que, para manter e aumentar o Capital Social é necessário um equilíbrio entre a capacidade de mobilização efetiva, o número de interações sociais e o número de seguidores. Por exemplo, um grande número de interações sociais e um grande número de seguidores de um agente com baixa capacidade de mobilização efetiva (que está associada ao número de ações realizadas), não garante um grande volume de CSB acumulado.

Na Figura 5 é apresentada uma comparação entre capacidade de mobilização efetiva (coluna 7, Mob.Ef.) número de interações sociais (coluna 8 , IS), número de seguidores (coluna 9, \#seg) e o volume de CSB (coluna 10, vCSB).

Na Figura 5a, GYM tem o maior número de seguidores e INH tem o menor número de seguidores. Além disso, GYM e INH tem as maiores capacidades de mobilização efetiva quando comparadas com as demais. Mobilizar uma rede de relacionamentos grande, como é o grupo de seguidores de GYM, certamente, é uma tarefa mais difícil que mobilizar um pequeno grupo como o de INH. Observando-se o número de interações sociais, GYM empenhou mais esforço na publicação de conteúdo que INH. Sendo assim, considerando o equilíbrio entre capacidade de mobilização efetiva, número de interações sociais e número de seguidores, GYM tem o volume de CSB maior que o volume de CSB de INH.

$\mathrm{Na}$ Figura 5b, a Página Institucional RVD tem o maior número de seguidores e a Página Institucional IPA tem o menor número de seguidores. Além disso, na Figura 3b, RVD e IPA tem capacidades de mobilização efetiva muito próximas. Mobilizar uma rede de relacionamentos grande, como é o grupo de seguidores de RVD, certamente, é uma tarefa mais difícil que mobilizar o pequeno grupo de seguidores de IPA. Além disso, observando-se o número de interações sociais, RVD empenhou mais esforço na publicação de conteúdo que IPA. Sendo assim, é razoável admitir que RVD tenha um CSB maior que de IPA. Na Figura 5b, o volume de CSB acumulado de RVD é maior que o volume de CSB acumulado de IPA.

Na comparação apresentada na Figura 5, confirmam que a capacidade de mobilização efetiva não se converte automaticamente em Capital Social Bourdieusiano, pois ela precisa ser equilibrada com o número de interações sociais e o número de seguidores. Como consequência, a medida de CSB aqui apresentada permite quantificar o esforço contínuo de sociabilidade de um agente Página Institucional necessária para manter e aumentar o volume do CSB. Esses resultados estão alinhados com a teoria de Bourdieu [4].

A abordagem e a medida do volume CSB, aqui detalhada, não tem pretensão de substituir ou invalidar as abordagens e medidas de Capital Social dentro de RSO já existentes Desejase que possam ser usadas em complementação e, de forma simplificada e direta, forneça resultados para serem comparados com outras abordagens.

\section{Generalização da Abordagem}

No intuito de verificar a generalização da abordagem, ou seja, sua capacidade potencial de aplicação em outras RSO, foi elaborado um experimento com o objetivo de apurar o volume do CSB acumulado em Perfis Institucionais na rede Twitter. Verificou-se que as duas instituições federais de ensino consideradas na análise de Páginas Institucionais do Facebook, também estavam presentes no Twitter: a primeira instituição tem apenas 9 campi com perfil institucional e a segunda instituição tem apenas 4. É importante destacar que perfis não institucionais estão fora do escopo desta pesquisa.

\subsection{Bases de dados e ETL}

Seguindo na aplicação da abordagem, como resultado das fases de identificação e coleta dos dados, foi construída uma base de dados para cada perfil institucional, ou seja, 13 bases de dados foram construídas. Nessas bases foram armazenadas informações como nome do perfil, identificador do perfil, identificador da postagem, conteúdo da postagem, tipo de mídia publicada na mensagem, data e hora da publicação, número de comentários, número de compartilhamentos internos (retweets) sem comentário, número de compartilhamento internos (retweets) com comentário e o número de curtidas. A polaridade da opinião expressa em cada tweet publicado foi analisada fazendo uso da API IBM Watson ${ }^{8}$, e incorporada nas bases de dados. Essa API realiza a classificação do sentimento contido no tweet como positivo, negativo ou neutro. O tratamento do conteúdo do tweet é feito via API, ou seja, não é feito nenhum tipo de pré-processamento do conteúdo do tweet antes do uso da API. Foram coletados no máximo 3.500 tweets de cada perfil publicados a partir 25 de agosto de 2020, totalizando 17.493 tweets coletados.

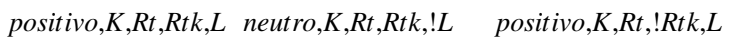
negativo,!K,Rt,Rtk,L positivo, $K, ! R t, R t k, L$ neutro, $K, R t, ! R t k, ! L$

Listagem 3. Exemplo de Base de Dados não-numérica

Seguindo na abordagem, os dados capturados foram transformados, preparando-os para etapa de extração de sequências

\footnotetext{
${ }^{8}$ http://www.redbooks.ibm.com/abstracts/sg247877.html?Open
} 
e uma base de dados não-numéricos foi construída para sua corresponde numérica. Na transformação, número de comentários maior que 0 foi representado por $K$ e igual a 0 por $! K$, número de compartilhamentos internos (retweets) sem comentário maior que 0 por $R t$ e igual a 0 por ! $R t$, número de compartilhamento internos (retweets) com comentário maior que 0 por Rtk e igual a 0 por !Rtk, por fim, o número de curtidas maior que 0 por $L$ e igual a 0 por $! L$. Um exemplo da organização dos dados em uma base não-numérica é apresentado na Listagem 3.

A perda de informação continua presente no processo de transformação de valores numéricos em não-numéricos há. Para minimizar os efeitos dessa perda, são mantidas 13 bases numéricas e 13 bases não-numéricas para confronto de informação. Em trabalhos futuros, valores como a média de curtidas, a média de comentários e a média de retweets poderão ser usados como pesos para caracterizar a parti- cipação dos seguidores. Essa estratégia pode minimizar os efeitos da perda de informação e poderá ser incorporada na abordagem como desdobramento e aprimoramento das contribuições da presente pesquisa.

\subsection{Sequências de Ações e Validação}

Partindo para a etapa de sequências de ações e sua va- lidação, foram extraídas sequências de tamanho 1, 2, 3, 4, 5. As sequências de ações extraídas de cada base de dados nãonuméricos de tamanho 4 são apresentadas na Listagem 4. As sequências de ações de tamanho 5 com sentimento de polaridade positiva são apresentadas na Listagem 5.

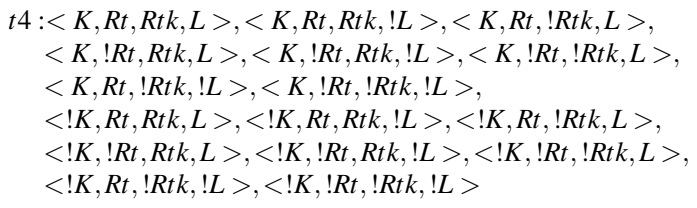

Listagem 4. Sequências de Ações Tamanho 4

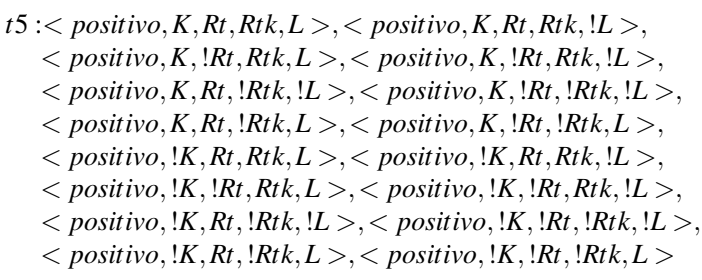

Listagem 5. Sequências de Ações Tamanho 5

As sequências de ações de tamanho 4 retratam no seu corpo uma associação entre a execução e/ou não das ações Comentar, Retweetar (sem e com comentário) e Curtir. As sequências de ações de tamanho 5 retratam no seu corpo, além da associação entre a execução e/ou não das referidas ações, a polaridade do tweet.

$\mathrm{Na}$ aplicação da abordagem, para cada perfil foi feita a validação das frequências de ocorrência de cada sequência aprendida, a partir do confronto do número de ocorrência de cada sequência pelo algoritmo GSP com os valores retornados pelas consultas SQL. Nesse confronto, a diferença dos valores foi igual a 0 para todos os perfis analisados, ou seja, nenhum dado ficou de fora do aprendizado de sequências.

$\mathrm{Na}$ Listagem 4 , a sequência $<$ !K, !Rt, !RtK, !L $>$ retrata a execução de 0 ações e está associada com a incapacidade de mobilização. Na Tabela 4, a incapacidade de mobilização está apresentada na coluna 2. Por outro lado, a sequência $<\mathrm{K}, \mathrm{Rt}$, RtK, L > retrata a execução das 4 ações Comentar, Retweetar sem comentário, Retweetar com comentário e Curtir. A capacidade de mobilização está associada com as sequências que contém ações executadas no seu corpo, portanto, com sequências que retratam a execução de 1, 2, 3 e 4 dentre as ações Comentar, Retweetar sem comentário, Retweetar com comentário e Curtir. Na Tabela 4, as frequências de ocorrência dessas sequências são apresentadas nas colunas 3 a 6 .

Pode ser observado que a implementação do algoritmo de extração de sequências, empregada na abordagem, é robusto o suficiente para se adaptar a qualquer conjunto de dados com quantidades de ações capturadas de diferentes RSO.

\subsection{Apuração do Capital Social Bourdieusiano}

Na etapa de apuração do CSB, na Tabela 4, a identificação de cada perfil institucional é apresentada na coluna 1, além de uma síntese da apuração das frequências de ocorrência de cada sequência aprendida. Na Listagem 4 , a sequência $<$ !K, !Rt, !RtK, !L $>$ retrata a execução de 0 ações e está associada com a incapacidade de mobilização. Na Tabela 4, a incapacidade de mobilização está na coluna 2 .

Por outro lado, a sequência $<\mathrm{K}$, Rt, RtK, L $>$ retrata a execução das 4 ações Comentar, Retweetar sem comentário, Retweetar com comentário e Curtir. A capacidade de mobilização está associada com as sequências que contém ações executadas no seu corpo, portanto, com sequências que retratam a execução de 1, 2, 3 e 4 dentre as ações Comentar, Retweetar sem comentário, Retweetar com comentário e Curtir. Na Tabela 4, as frequências de ocorrência dessas sequências são apresentadas nas colunas 3 a 6 .

Ainda na Tabela 4, são apresentadas a apuração da capacidade de mobilização que cada agente perfil institucional possui (coluna 7), a apuração da capacidade de mobilização efetiva (coluna 8), o número de interações capturadas de cada perfil e analisadas para obtenção das frequências (coluna 9), o número de seguidores (coluna 10) e o volume de Capital Social Bourdieusiano acumulado (coluna 11).

Seguindo na Tabela 4, coluna 12 , está a capacidade de mobilização efetiva obtida a partir tweets com sentimento positivo. Esse valor foi obtido da Equação 1 a partir das frequências de ocorrência das sequências apresentadas na Listagem 5. A coluna 13, apresenta a capacidade de mobilização efetiva obtida a partir tweets com sentimento neutro, que também foi obtida da Equação 1 a partir das frequências das sequências de tamanho 5 com sentimento neutro no seu corpo.

Por fim, o percentual que sinaliza o impacto dos tweets positivos e neutros na composição capacidade de mobilização efetiva de cada perfil, que está na coluna 14 , foi obtido 
somando-se Mob.Ef .positivo e Mob.Ef.neutro e se dividindo essa soma pela capacidade de mobilização efetiva (Mob.Ef .).

Pode ser constatado que o cômputo das medidas de capacidade de mobilização efetiva e do volume de CSB, empregado na abordagem, é robusto o suficiente para se adaptar a sequências com ações de diferentes RSO.

\subsection{Discussão sobre a Generalização}

Na generalização da abordagem, a partir de um experimento com dados de Perfis Institucionais na rede Twitter foi possível observar alguns pontos de destaque. As ações executadas são o elemento central da abordagem e do sistema de trocas de Bourdieu. Elas são tratadas na extração automática de sequências via GSP independentemente do conjunto de ações de cada RSO. Isso significa que, para cada conjunto de ações cada RSO, um formato de conjunto de sequências. O formato é dirigido pelos dados. A abordagem e suas respostas não estão atreladas nem a quantitativos de ações, a formatos específicos ou a tamanho das sequências.

As limitações da presente abordagem poderão ser superadas em trabalhos futuros. Para minimizar os efeitos da perda de informação na transformação dos dados numéricos em não-numéricos, valores como a média de curtidas, a média de comentários, a média de compartilhamentos, a média de retweets, poderão ser usadas como pesos para caracterizar a participação dos seguidores dentro de cada Página ou Perfil Institucional. Um aprimoramento possível é relacionar o número de usuários ativos (que participam efetivamente das interações sociais a partir da execução de ações) com o número de seguidores, e utilizar essa relação como fator de ponderação do tamanho da rede.

Os resultados obtidos com a análise de Perfis Institucionais na rede Twitter estão alinhados com a teoria de Bourdieu da mesma forma que os resultados da análise de Páginas Institucionais do Facebook. Maiores detalhes a respeito do experimento com a análise Perfis Institucionais na rede Twitter podem ser encontrados em [12]. Nesse trabalho ainda pode ser visto que a abordagem aqui apresentada foi generalizada para a construção de um processo sistemático. A partir da definição desse processo, uma ferramenta para dispositivos móveis que permite a coleta e rotulagem de dados do Twitter foi construída e é apresentada em [39].

\section{Conclusão}

Com o suporte da teoria do sociólogo Pierre Bourdieu, no presente artigo foi apresentada uma nova abordagem para computar o volume de Capital Social Bourdieusiano acumulado dentro de Páginas Institucionais do Facebook. A abordagem toma proveito das implicações decorrentes do estudo do grafo da atividade dos usuários como um subgrafo da rede de conexões, para construir uma medida da capacidade de mobilização efetiva e uma medida do volume de CSB.

A principal contribuição desta pesquisa é a apresentação de uma abordagem que permite mensurar o Capital Social Bourdieusiano em Páginas ou Perfis Institucionais a partir de duas medidas: uma medida da capacidade de mobilização efetiva e uma medida do volume de CSB acumulado.

A medida de capacidade de mobilização efetiva produz resultados que não são proporcionais nem ao número de interações sociais nem ao do número de seguidores, e permite identificar a capacidade que um agente tem de estimular sua rede a realizarem trocas simbólicas e se reconhecerem mutuamente, nas quais há mais ações executadas.

A medida do volume CSB promove equilíbrio entre a) a capacidade de mobilização efetiva, b) o número de interações sociais e c) o tamanho da rede de conexões. Deve ser destacado que a medida de CSB aqui apresentada é capaz de quantificar o esforço incessante de sociabilidade do agente.

Conforme foi apresentado, os resultados obtidos estão alinhados com a teoria de Bourdieu no que se refere 1) a representação do sistema de trocas entre agentes e sua rede de conexões, 2) a capacidade de mobilização efetiva que não é proporcional ao número de interações sociais capturadas, 3) a capacidade de mobilização efetiva do agente que independe do tamanho da sua rede de relacionamentos, 4) a capacidade de mobilização efetiva que não é convertida automaticamente em CSB, e 5) a manutenção e expansão do Capital Social pressupõe um esforço incessante de sociabilidade.

A abordagem pode ser avaliada quanto a flexibilidade para incorporar novas ações como: compartilhamento externo de conteúdo; outros tipos de reação além de Curtir; e ainda, o número de visualizações em um vídeo. Quanto a versatilidade, a abordagem pode ser testada em redes como LinkedIn, Twitter e Youtube.

\section{Agradecimentos}

Os autores agradecem ao Programa Institucional de Bolsas de Iniciação em Desenvolvimento Tecnológico e Inovação (PIBITI) e ao Programa Institucional de Bolsas de Iniciação Científica (PIBIC) do Instituto Federal de Goiás (IFG), apoiados pelo Conselho Nacional de Desenvolvimento Científico e Tecnológico (CNPq). Também agradecem ao Fomento Universal para Pesquisadores do Câmpus Inhumas do IFG.

\section{Contribuições dos autores}

Alan Keller Gomes é responsável pela escrita e organização do artigo, além da coordenação da pesquisa. Em conjunto com Kaique Matheus R. Cunha e Guilherme Augusto da S. Ferreira, contribuíram na revisão de literatura e fundamentação teórica, no estudo dos materiais e métodos, na elaboração da estratégia de validação e generalização da proposta, além da apuração e discussão dos resultados.

\section{Referências}

[1] SANTOS, F. C.; CYPRIANO, C. P. Redes sociais, redes de sociabilidade. Revista Brasileira de Ciências Sociais, scielo, v. 29, p. 63-78, 06 2014. ISSN 0102-6909. Disponível em: <https://doi.org/10.1590/S0102-69092014000200005>. 
[2] IGNATOW, G.; ROBINSON, L. Pierre bourdieu: theorizing the digital. Information, Communication \& Society, Routledge, v. 20, n. 7, p. 950-966, 2017. Disponível em: $<$ https://doi.org/10.1080/1369118X.2017.1301519>.

[3] STERNE, J. Bourdieu, technique and technology. Cultural Studies, Routledge, v. 17, p. 367-389, 2003. Disponível em: <https://doi.org/10.1080/ 0950238032000083863a>.

[4] BOURDIEU, P. The forms of capital. In: Handbook of Theory and Research for the Sociology of Education. NY,USA: Greenw. Press, 1986. p. 241-258.

[5] RECUERO, R. O capital social em rede: Como as redes sociais na internet estão gerando novas formas de capital social. Contemporânea, v. 10, n. 3, p. 597-617, 2012. Disponível em: <http://dx.doi.org/10.9771/ 1809-9386contemporanea.v10i3.6295>.

[6] JULIEN, C. Bourdieu, social capital and online interaction. Sociology, SAGE Publications Sage UK: London, England, v. 49, n. 2, p. 356-373, 2015. Disponível em: $<$ https://doi.org/10.1177/0038038514535862>.

[7] ELOIRE, F. The bourdieusian conception of social capital: a methodological reflection and application. In: TAYLOR \& FRANCIS. Forum for Social Economics. 2015. v. 47, n. 3-4, p. 322-341. Disponível em: $<$ https://doi.org/10.1080/07360932.2015.1028084>.

[8] PRADO, L. Á.; FROGERI, R. F. Marketing de influência - um novo caminho para o marketing por meio dos digital influencers. Interação-Revista de Ensino, Pesquisa e Extensão, v. 19, n. 2, p. 43-58, 2017. Disponível em: $<$ https://doi.org/10.33836/interacao.v19i2.136>.

[9] BOSHMAF, Y. et al. The socialbot network: when bots socialize for fame and money. In: Proceedings of the 27th Annual Computer Security Applications Conference - ACSAC'11. [s.n.], 2011. p. 93-102. Disponível em: $<$ https://doi.org/10.1145/2076732.2076746>.

[10] CUNHA, K. M. R.; GOMES, A. K. Measurement of mobilization capacity via actions sequence learning within institutional facebook fan pages. In: Proceedings of the 25th Brazilian Symposium on Multimedia and the Web. [S.1.]: ACM, 2019. (WebMedia 2019), p. 317-320. ISBN 9781450367639.

[11] CUNHA, K. M. R.; GOMES, A. K. Mensuração do capital social acumulado a partir de interações sociais em páginas institucionais no facebook. In: Anais do IX Brazilian Workshop on Social Network Analysis and Mining. Cuiabá, MT, Brasil: SBC, 2020. (BraSNAM 2020), p. 85-96.

[12] FERREIRA, G. A. da S.; GOMES, A. K. A systematic process for computing bourdieusian social capital within institutional profiles on twitter. In: Proceedings of the Brazilian Symposium on Multimedia and the Web. New York, NY, USA: ACM, 2021. (WebMedia'21), p. 17-24. ISBN 9781450386098. Disponível em: <https://doi.org/10.1145/3470482.3479437>.
[13] COLEMAN, J. S. Social capital in the creation of human capital. American journal of sociology, Univer. of Chicago Press, v. 94, p. S95-S120, 1988. Disponível em: <https: //www.journals.uchicago.edu/doi/abs/10.1086/228943\#>.

[14] LIN, N.; COOK, K. S.; BURT, R. S. Social capital: Theory and research. [S.1.]: Transaction Publishers, 2001.

[15] PUTNAM, R. Social capital: Measurement and consequences. Canadian journal of policy research, v. 2, n. 1, p. 41-51, 2001. Disponível em: <https://www.alnap.org/ system/files/content/resource/files/main/1825848.pdf>.

[16] GRANOVETTER, M. The strength of weak ties: A network theory revisited. Sociological theory, JSTOR, p. 201-233, 1983. Disponível em: $<$ https://doi.org/10.2307/202051>.

[17] BURT, R. S. The contingent value of social capital. Administrative science quarterly, JSTOR, p. 339-365, 1997. Disponível em: <https://doi.org/10.2307/2393923>.

[18] ABBOTT, A. Reflections on the future of sociology. Contemporary Sociology, [American Sociological Association, Sage Publications, Inc.], v. 29, n. 2, p. 296-300, 2000. ISSN 00943061, 19398638. Disponível em: <http://www.jstor.org/stable/2654383>.

[19] WYNN, J. R. Digital sociology: emergent technologies in the field and the classroom. In: WILEY ONLINE LIBRARY. Sociological Forum. 2009. v. 24, n. 2, p. 448-456. Disponível em: $<$ https://doi.org/10.1111/j.1573-7861.2009.01109.x>.

[20] LUPTON, D. Digital sociology. [S.1.]: Routledge, 2014. [21] BOURDIEU, P. O Poder Simbólico. Difel Bertrand Brasil, 1980. ISBN 9789724416663. Disponível em: <https://pt.scribd.com/document/238564751/ 7-O-Poder-Simbolico-Bourdieu>.

[22] BOURDIEU, P. Language and Symbolic Power. [S.1.]: John B. Thompson Ed., Polity Press, 1991. (Social theory). ISBN 9780674510418.

[23] THIRY-CHERQUES, H. R. Pierre Bourdieu: a teoria na prática. Revista de Administração Pública, scielo, v. 40, p. 27-53, 02 2006. ISSN 0034-7612. Disponível em: $<$ http://www.scielo.br/scielo.php?script=sci_arttext\&pid= S0034-76122006000100003\&nrm=iso>.

[24] KAZIENKO, P.; MUSIAŁ, K. Social capital in online social networks. In: SPRINGER. International Conference on Knowledge-Based and Intelligent Information and Engineering Systems. 2006. p. 417-424. Disponível em: $<$ https://link.springer.com/chapter/10.1007/11893004_54>.

[25] ELLISON, N. B.; STEINFIELD, C.; LAMPE, C. The benefits of facebook friends: Social capital and college students' use of online social network sites. Journal of Computer-Mediated Communication, v. 12, n. 4, p. 1143-1168, 07 2007. ISSN 1083-6101. Disponível em: <https://doi.org/10.1111/j.1083-6101.2007.00367.x>. 
[26] DYER, H. T. The presentation of selfie in everyday life: Considering the relationship between social media design and user in the online actions and interactions of young people. In: Proceedings of International Conference on Social Media \& Society. New York, NY, USA: ACM, 2017. p. 6:1-6:11. ISBN 978-1-4503-4847-8. Disponível em: $<$ http://doi.acm.org/10.1145/3097286.3097292>.

[27] SCHAMS, S.; HAUFFA, J.; GROH, G. Analyzing a user's contributive social capital based on acitivities in online social networks and media. In: Proceedings of the The Web Conference. [s.n.], 2018. (WWW'18), p. 1457-1464. ISBN 978-1-4503-5640-4. Disponível em: <https://doi.org/10.1145/3184558.3191593>.

[28] SU, C. C.; CHAN, N. K. Predicting social capital on facebook: The implications of use intensity, perceived content desirability, and facebook-enabled communications practices. Computers in Human Behavior, v. 72, p. 259-268, 2017. ISSN 0747-5632. Disponível em: <http://www.sciencedirect. com/science/article/pii/S0747563217301395>.

[29] WILSON, C. et al. Beyond social graphs: User interactions in online social networks and their implications. Transactions on the Web (TWEB), ACM, New York, NY, USA, v. 6, n. 4, nov. 2012. ISSN 1559-1131. Disponível em: $<$ https://doi.org/10.1145/2382616.2382620>.

[30] NAZIR, A. et al. Beyond friendship: Modeling user activity graphs on social network-based gifting applications. In: Proceedings of the Internet Measurement Conference - IMC'12. NY, USA: ACM, 2012. p. 467-480. ISBN 9781450317054. Disponível em: $<$ https://doi.org/10.1145/2398776.2398826>.

[31] CUNHA, K. M. R.; COSTA, R. L. d.; GOMES, A. K. A measurement approach to the bourdieusian social capital within facebook institutional pages. In: XVII Brazilian Symposium on Information Systems. New York, NY, USA: ACM, 2021. (SBSI 2021). ISBN 9781450384919. Disponível em: <https://doi.org/10.1145/3466933.3466964>.

[32] SKINNER, B. F. Science and Human Behavior. [S.1.]: New York: Macmillan, 1953.
[33] MECHNER, F. Behavioral contingency analysis. Behavioral Processes, ScienceDirect, Elsevier B.V., v. 78, n. 2, p. 124-144, 2008. Disponível em: $<$ https://doi.org/10.1016/j.beproc.2008.01.013>.

[34] GOMES, A. K.; PIMENTEL, M. d. G. C. A technique for human-readable representation e evaluation of mediabased social interactions in social networks. In: Proceedings of the 17th Brazilian Symposium on Multimedia and the Web. SBC, 2011. (WebMedia 2011), p. 119-126. Disponível em: $<$ http://dl.acm.org/citation.cfm?id=3021508.3021527>.

[35] GOMES, A. K.; PIMENTEL, M. d. G. C. Evaluation of media-based social interactions: Linking collective actions to media types, applications, and devices in social networks. In: _. Online Collective Action: Dynamics of the Crowd in Social Media. Vienna: Springer Vienna, 2014. p. 75-95. ISBN 978-3-7091-1340-0. Disponível em: <http://dx.doi.org/10.1007/978-3-7091-1340-0\5>.

[36] KIMBALL, R.; ROSS, M. The Data Warehouse Toolkit: The Complete Guide to Dimensional Modeling. 2nd. ed. NY, USA: John Wiley \& Sons, 2002. ISBN 0471200247, 9780471200246.

[37] AGRAWAL, R.; SRIKANT, R. Mining sequential patterns. In: Proceedings of the International Conference on Data Engineering (ICDE '95). IEEE, 1995. p. 3-14. ISBN 0-8186-6910-1. Disponível em: $<$ https://ieeexplore.ieee.org/abstract/document/380415>.

[38] TAN, P.-N.; STEINBACH, M.; KUMAR, V. Introduction to Data Mining. [S.1.]: Addison Wesley, 2005. ISBN 0321321367.

[39] FERREIRA, G. A. da S.; GOMES, A. K. A mobile tool for collecting and labeling data on twitter's network sociability practices. In: Proceedings of the Brazilian Symposium on Multimedia and the Web. New York, NY, USA: ACM, 2021. (WebMedia'21), p. 25-28. ISBN 9781450386098. Disponível em: <https://doi.org/10.1145/3470482.3479438>. 